Linköping Studies in Science and Technology

Licentiate Thesis No. 1728

\title{
Thin Film Synthesis of \\ New Nanolaminated Ternary Carbides
}

\author{
Chung-Chuan Lai
}

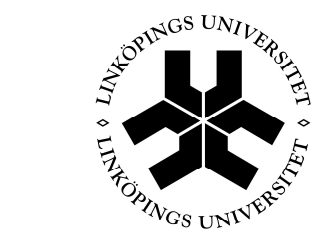

LINKÖPINGS UNIVERSITET

\author{
Thin Film Physics Division \\ Department of Physics, Chemistry and Biology (IFM) \\ Linköping University \\ SE-581 83 Linköping, Sweden
}

Linköping 2015 
(C) Chung-Chuan Lai 2015

Printed in Sweden by LiU-Tryck 2015

ISSN 0280-7971

ISBN 978-91-7685-960-5 


\section{Abstract}

Ternary transition metal carbides with inherently nanolaminated crystal structure are a class of materials with typically higher damage tolerance, better machinability and lower brittleness compared to the binary counterparts, yet retaining their satisfactory electrical and thermal conductivity. Their interesting properties can be related to the laminated structure. Though studies of their properties based on calculations and bulk materials have suggested potential thin film applications, such as high temperature hard coatings and electrical contacts, a relatively small number of these phases have been synthesized as thin films. Investigation of thin film deposition of these inherently nanolaminated materials further the understanding of their phase formation and crystal growth.

Motivated by predicted superconductivity and thermoelectric properties of molybdenum carbides and related layered molybdenum compounds, nanolaminated materials in the Mo-Ga$\mathrm{C}$ ternary system were studied. Apart from the previously reported $\mathrm{Mo}_{2} \mathrm{GaC}$, a new layered carbide, $\mathrm{Mo}_{2} \mathrm{Ga}_{2} \mathrm{C}$, was synthesized in both thin film and bulk form with a postulated crystal structure related to $\mathrm{Mo}_{2} \mathrm{GaC}$. The proposed structure was further validated by first principles calculations, showing higher stability compared to other crystal structure as well as other competing phases. The calculated lattice parameters were consistent with values from Rietveld analysis of X-ray and neutron diffraction patterns. In addition, both scanning transmission electron microscopy and X-ray photoelectron spectroscopy showed experimental evidence of the close structural-chemical relation between $\mathrm{Mo}_{2} \mathrm{Ga}_{2} \mathrm{C}$ and $\mathrm{Mo}_{2} \mathrm{GaC}$.

Driven by a need of high temperature protective coatings in nuclear applications, $\mathrm{Zr}$-based nanolaminated carbides have become more attractive. In this work, another nanolaminated carbide, $\mathrm{Zr}_{2} \mathrm{Al}_{3} \mathrm{C}_{4}$, was synthesized in thin film form by pulsed cathodic arc deposition. Formation of the $\mathrm{Zr}_{2} \mathrm{Al}_{3} \mathrm{C}_{4}$ phase and its competing phases was studied with $\mathrm{X}$-ray diffraction of thin films deposited with varying incoming flux compositions, temperatures and substrate 
materials. On $4 \mathrm{H}-\mathrm{SiC}(001)$ substrates, highly phase-pure epitaxial $\mathrm{Zr}_{2} \mathrm{Al}_{3} \mathrm{C}_{4}$ films were formed, whereas depositions on $\mathrm{Al}_{2} \mathrm{O}_{3}(001)$ substrates resulted in competing phases. A growth behavior similar to that of nanolaminated $M_{n+1} A X_{n}$ phases ( $M$ is a group 3-7 transition metal; $A$ is commonly a group 13-14 element; $X$ is $\mathrm{C}$ or $\mathrm{N} ; n=1-3$ ) was observed, despite the structuraland chemical differences between $\mathrm{Zr}_{2} \mathrm{Al}_{3} \mathrm{C}_{4}$ and MAX phases. 


\section{Preface}

This presented licentiate thesis is part of my doctoral study in Material Design Group, Thin

Film Physics Division, Department of Physics, Chemistry and Biology (IFM), Linköping University, Sweden. The work included is a summary of my work from between January 2013 to August 2015. The aim of my work is to synthesize and to explore new nanolaminated carbide phases, primarily in thin film form. The project is funded by the Swedish Foundation for Strategic Research (SSF) through the Synergy Grant FUNCASE. 


\section{Appended Papers}

\section{Paper I}

\section{$\mathrm{Mo}_{2} \mathrm{Ga}_{2} \mathrm{C}:$ a New Ternary Nanolaminated Carbide}

C. Hu, C.-C. Lai, Q. Tao, J. Lu, J. Halim, L. Sun, J. Zhang, J. Yang, B. Anasori, J. Wang, Y. Sakka, L. Hultman, P. Eklund, J. Rosen and M. W. Barsoum

Chem. Comm. 51 (2015) 6560-6563

In Paper I, I took part in design of the experiments, and performed a major part of the thin film synthesis. I acquired and analyzed X-ray diffraction patterns on thin film samples, and took part in other characterizations. I wrote a part of the paper.

\section{Paper II}

\section{Structural and Chemical Determination of the New Nanolaminated Carbide $\mathrm{Mo}_{2} \mathrm{Ga}_{2} \mathrm{C}$ from First Principles and Materials Analysis}

C.-C. Lai, R. Meshkian, M. Dahlqvist, J. Lu, L.-Å. Näslund, O. Rivin, E. N. Caspi, O. Ozeri, L. Hultman, P. Eklund, M. W. Barsoum and J. Rosen

Acta Mater. 99 (2015) 157-164

In Paper II, I took part in design of the experiments and in the thin film synthesis. I prepared thin film specimens for other experiments, and took part in other characterization. I wrote a major part of the paper. 


\section{Paper III}

\section{Synthesis and Characterization of $\mathrm{Zr}_{2} \mathrm{Al}_{3} \mathrm{C}_{4}$ Thin Films}

C.-C. Lai, M. D. Tucker, J. Lu, J. Jensen, P. Eklund, and J. Rosen

Manuscript in Final Preparation

In Paper III, I took part in design of the experiments, and performed a major part of the thin film synthesis. I acquired and analyzed X-ray diffraction patterns, and prepared specimen for other characterization. I wrote a major part of the manuscript. 


\section{Acknowledgement}

Firstly, I would like to give my appreciations to my main supervisor, Johanna Rosén, and my co-supervisor, Per Eklund, for their timely advice, encouragement, and discussion with me.

I would also like to thank Materials Design group members:

Lars-Åke Näslund, Árni Ingason, Igor Zhirkov, Oleksiy Vozniy, Martin Dahlqvist, Aurelija Mockute, Andreas Thore, Andrejs Petruhins, Rahele Meshkian, Quanzheng Tao, and Nils Nedfors

...for offering me lots of helps, ideas and talks around.

Special thanks to Mark Tucker, our former colleague, who gave me important supports in the first year of my doctoral study, and helps me continuously after he left from IFM.

Finally, lots of appreciations to my dearest family, Chang-Hsien Lai, Hsiu-Mei Lin, ChungYu Lai, and girlfriend, Yi-Ping Liu, for their solid backings from Taiwan. 


\section{Table of Contents}

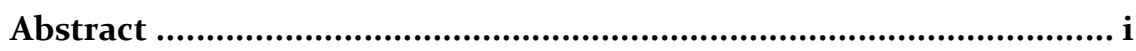

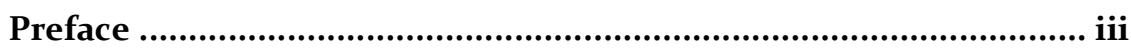

Appended Papers ............................................................................. v

Acknowledgment .......................................................................... vii

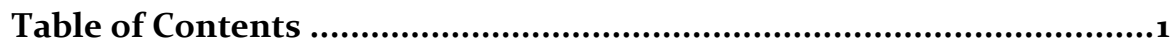

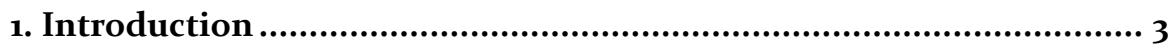

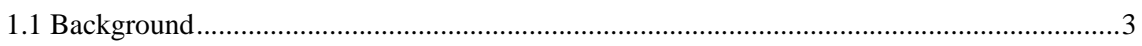

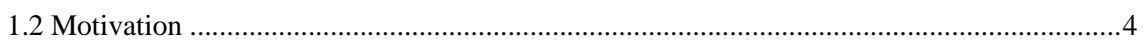

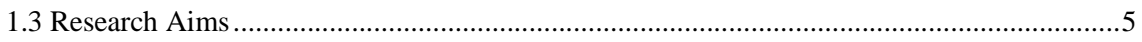

2. Transition-Metal Carbides ..................................................................... 7

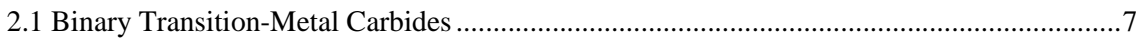

2.2 Ternary Transition-Metal Carbides .............................................................................

2.3 Inherently Nanolaminated Carbides .............................................................................. 10 
3. Thin Film Synthesis.............................................................. 15

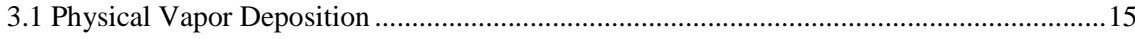

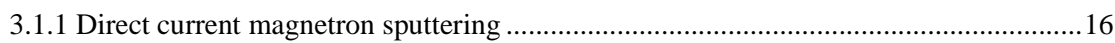

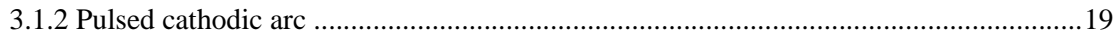

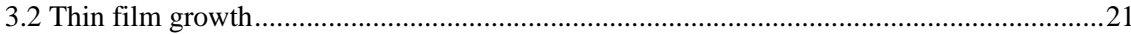

4. Thin Film Characterization Techniques .......................................25

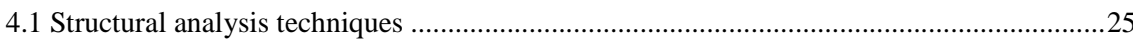

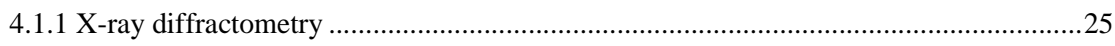

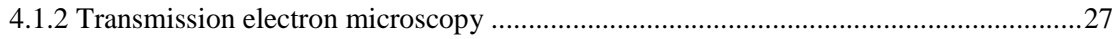

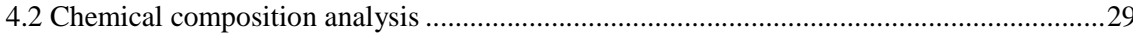

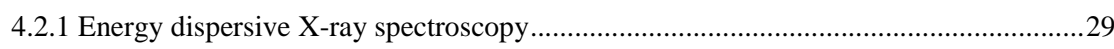

4.2.2 Time-of-flight elastic recoil detection analysis........................................................29

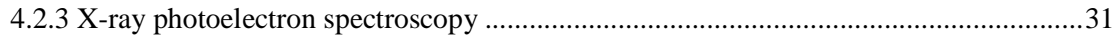

5. Summary of Included Papers .....................................................3

5.1 Discovery of a new nanolaminated carbide, $\mathrm{Mo}_{2} \mathrm{Ga}_{2} \mathrm{C}$ (Paper I) .........................................33

5.2 Structural determination of the new carbide, $\mathrm{Mo}_{2} \mathrm{Ga}_{2} \mathrm{C}$ (Paper II)......................................33

5.3 Phase stability of $\mathrm{Zr}_{2} \mathrm{Al}_{3} \mathrm{C}_{4}$ in thin film synthesis (Paper III) ...........................................34

6. Outlines for Future Work ..................................................................35

7. Bibliography....................................................................................... 37

Paper I - III 


\section{Introduction}

\subsection{Background}

Transition-metal carbides (TMCs) are compounds composed by carbon and transition elements, and they exhibit some general properties: hard, brittle, highly refractory and chemically inert [1]. In combination with their satisfactory electrical and thermal conductivity, they have been put into many bulk and thin film applications, for example, $\mathrm{WC}_{-} \mathrm{W}_{2} \mathrm{C}$ molds and wire-drawing dies [2], cemented-carbide machine tools [2], wear-resistant and hard coatings (as composite materials) [3] [4], $\mathrm{Mo}_{2} \mathrm{C}$ catalyst coatings [5], and protective coatings for corrosive environments [6].

Research and production of most TMCs in history start from their binary systems, i.e. single transition element and carbon system, though some of them are first identified in oxycarbide or carbonitride forms [1]. In the 1890's and 1900's, Henri Moissan synthesized a good number of refractory TMCs of group 4-6 elements within electric furnace, which was originally an invention for synthesizing artificial diamonds [7] [8]. In the beginning of $20^{\text {th }}$ century, the attempts of applying pure TMCs, for example $\mathrm{WC}$ and $\mathrm{W}_{2} \mathrm{C}$, were not very successful as refractory and abrasive tool materials, due to their high brittleness and therefore low damage tolerance [9]. However, more or less at the same time, the inventions of cemented carbide tools, where TMCs work as reinforcement in relatively soft material matrices, has turned out to be a great success in production industry. Thereafter, these materials started to attract more attention from the field and inspired series of careful examinations on the physics behind their properties in mid- $20^{\text {th }}$ century $[6]$. 
Partly inspired by the idea of enhancing the high temperature performance of binary TMCs, which are crucial for materials as machine tools or protective coatings [6] [10], extensive work has been carried out on synthesizing ternary carbides since 1960's, see examples in references [11] [12] [13] [14]. These then-new reported carbides were mostly phases with a group 13-14 elements as the third element, or solid solutions with boride, nitride and oxide.

In investigations of ternary carbide systems, many stable and metastable phases were identified with nanolaminated structures, for example $\mathrm{Ti}_{3} \mathrm{SiC}_{2}, \mathrm{Zr}_{3} \mathrm{Al}_{3} \mathrm{C}_{5}$, and $\mathrm{Mo}_{2} \mathrm{BC}$, which are often softer but less brittle, more damage tolerant, stiffer, slightly less conductive to electricity and heat than their binary counterparts, and they can be machined more easily compared to most other ceramics. A well-known example for the nanolaminated phases is the MAX phases, which is a group of phases with a general formula $M_{n+1} A X_{n}$, where $M$ is a group 3-6 element; $A$ is commonly a group 13-14 element; $X$ is either $\mathrm{C}$ or $\mathrm{N} ; n=1,2$ or 3 [15].

\subsection{Motivation}

As the entire TMC research area evolves from binary to multiple-element systems and from isostructural solid solutions to nanolaminates, more complicated growth and properties are observed from the synthesis process and characterization of the new materials. Experimental and theoretical works have been reported over past 50 years that compare and combine new phases within the TMC family. However, despite that ternary nanolaminated TMCs have been reported with many interesting properties, the studies in thin films are still in minority compared to bulk synthesis [16]. A broad scope of my work is to assess the material science of these nanolaminated carbide systems from the aspect of their crystal growth and phase competition during the synthesis in thin film form. Molybdenum carbides have been reported as superconductors in various binary and ternary forms [17] [18] [19] and as catalytic materials in substitution of metallic Mo and high coast Pt/Pd [20] [21]. At the same time, molybdenum compounds in laminated structures have been studied for interesting properties, e.g. $\mathrm{MoS}_{2}$ for tribology properties [22] [23] and $\mathrm{Mo}_{2} \mathrm{C}$ for thermoelectric properties [24] [25]. Though molybdenum carbide-based nanolaminated phases are similarly attractive for their properties, so far only two phases have been reported: $\mathrm{Mo}_{2} \mathrm{GaC}$ and $\mathrm{Mo}_{2} \mathrm{BC}$. In this work, we discovered a new nanolaminated phase, $\mathrm{Mo}_{2} \mathrm{Ga}_{2} \mathrm{C}$, whose structure was further investigated by a comprehensive analysis of theoretical calculations and various experimental techniques (see Paper I and II). 
Zirconium carbides in ternary forms, on the other hand, have been suggested as a reinforcing candidate for zirconium-alloy claddings in nuclear fuel tubes, due to their improved high temperature chemical stability and mechanical properties, as well as the low neutron absorption cross-section of $\mathrm{Zr}$ itself [26]. Although none of the three known types of MAX phases in $\mathrm{Zr}$-Al-C system has been reported experimentally, other nanolaminated carbides, such as $\mathrm{Zr}_{2} \mathrm{Al}_{3} \mathrm{C}_{4}$ and $\mathrm{Zr}_{3} \mathrm{Al}_{3} \mathrm{C}_{5}$, have been reported with bulk synthesis [11] [27] [28]. Here, the first nearly phase pure $\mathrm{Zr}_{2} \mathrm{Al}_{3} \mathrm{C}_{4}$ thin films was deposited, where the formation of the primary and impurity phases were studied in relations with input composition, substrate temperature and substrate materials applied during depositions (Paper III).

\subsection{Research Aims}

The aims of my work are to

I. Synthesize new nanolaminated carbide thin films within Mo-Ga-C and $\mathrm{Zr}-\mathrm{Al}-\mathrm{C}$ systems.

II. Study the relation between the new nanolaminated phases with known $M_{n+1} A X_{n}$ layered phase family, in terms of crystal structure and growth.

III. Determine the effect of deposition parameters on the phase formation in $\mathrm{Zr}_{2} \mathrm{Al}_{3} \mathrm{C}_{4}$ thin films. 


\section{Transition-Metal Carbides}

\subsection{Binary Transition-Metal Carbides}

Carbides are compounds formed with carbon and other elements with lower electronegativity ${ }^{1}$, where solid state carbide phases can be found in, for example, the group 1-2 metals [29] [30], the transition metals [6], the rare-earth metals [31], and B, Al, and Si. The carbide-forming elements can be roughly sorted by three classes depending on different types of bonding. The carbides formed with larger differences, e.g. the group 1-2 metals, rare-earth metals and $\mathrm{Al}$, exhibit a stronger ionic bonding and salt-like properties, while the ones formed with smaller differences, e.g. $\mathrm{B}$ and $\mathrm{Si}$, share a more covalent-type of bonds. The third group, the transition-metal carbides (TMCs), exhibit a mixing-type of bonds with covalent, ionic and metallic properties [32].

The formation of the carbide phases and their consequent properties are specifically related with the electron configurations and the atomic size of the transition metals, hence following certain periodic trends [33]. As a general rule of thumb, their most stable carbide forms reduce in thermodynamic stability when the valence electron of transition metals increase in d-orbit. Evidently, in the normal pressure condition, the standard enthalpy of formation for 3d-orbit TMCs becomes less negative in the value when moving from $\mathrm{Ti}$ to $\mathrm{Fe}$, while only metastable carbide phases have been reported for group 8-10 (e.g. $\mathrm{Fe}_{3} \mathrm{C}, \mathrm{Co}_{2} \mathrm{C}$ and $\mathrm{Ni}_{3} \mathrm{C}$ ) and no stable phase has been

\footnotetext{
${ }^{1}$ Note that electronegativity is a crude way describing a relative tendency for an element to take in or loss electrons in contact with other elements. It is, however, dependent to the valence number of an element. Here we only consider the electronegativity in the ground state of elements.
} 


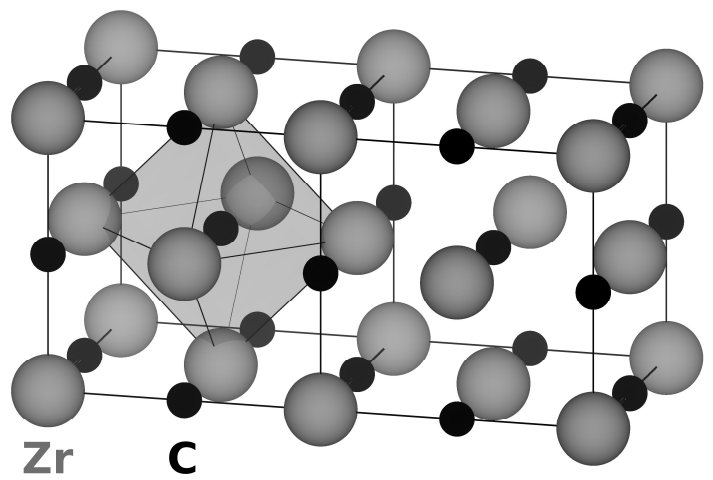

Figure 2-1. An illustration of two unit cells of $\mathrm{ZrC}$, sitting in horizontal direction, in the rock-salt structure (space group $F m-3 m)$. The $M_{6} \mathrm{C}(M=\mathrm{Zr})$ octahedron is indicated with a $\mathrm{C}$ atom in the center of the unit cell at left.

reported in group 11-12 (e.g. $\mathrm{Cu}, \mathrm{Zn}$ ) [34]. Notably at thermal equilibria of group 3 to 7 metal and carbon binary system, their most $\mathrm{C}$-rich carbides form in structures that can only accommodate less carbon atoms, e.g. $\mathrm{Sc}_{3} \mathrm{C}_{4}, \mathrm{TiC}, \mathrm{VC}, \mathrm{Cr}_{3} \mathrm{C}_{2}$ and $\mathrm{Mn}_{7} \mathrm{C}_{3}$, when increasing atomic number. In addition, the $\mathrm{Cr}-\mathrm{C}, \mathrm{Mn}-\mathrm{C}$ and $\mathrm{Fe}-\mathrm{C}$ system are often discussed with low carbon-concentration (<10 at.\%) and at high temperature $\left(>500{ }^{\circ} \mathrm{C}\right)$, where most of their metastable carbides can be produced [35].

Carbides from group 3-6 are mostly interesting for their wear and corrosion resistant, highly refractory and thermally and electrically conductive properties [6] [10]. The group 3-6 elements can form carbide phases in a common rock-salt structure (space group $F m \overline{3} m$ ), which has facecentered cubic lattice of transition metal atoms with carbon atoms sitting in each octahedral interstitial site, forming $M_{6} \mathrm{C}$ octahedrons, see Figure 2-1. Since the occupancy of the interstitial sites are often less than 1, the cubic carbide phases are sometimes written as $M C_{x}$, when $M$ is a group 3-6 metal; $x$ is usually 0.6 - 0.95 for group 4 metals but becomes narrower in range when moving to other groups. The stoichiometry of the cubic mono-carbide has significant effect on properties, but the trend is not the same for all TMCs, e.g. when increasing the C-occupancy the hardness increases for $\mathrm{Ti}, \mathrm{Zr}$ and $\mathrm{Hf}$, but decreases for $\mathrm{Nb}$ and $\mathrm{Ta}$ [13]. 
Meanwhile, the rock-salt cubic phase is the only stable carbide phase of the group 4 elements ( $\mathrm{Ti}$, $\mathrm{Zr}$ and $\mathrm{Hf}$ ), and is a metastable phase of the group 3 and 6 elements (Sc, Y, Cr, Mo and W). For the group 5 elements $(\mathrm{V}, \mathrm{Nb}$ and $\mathrm{Ta}$ ), non-stoichiometric rock-salt cubic phase tends to undertake order transformation at high temperature, leading to ordering phases such as $\mathrm{V}_{8} \mathrm{C}_{7}, \mathrm{~V}_{6} \mathrm{C}_{5}, \mathrm{Nb}_{6} \mathrm{C}_{5}$ and possibly $\mathrm{Ta}_{6} \mathrm{C}_{5}[\mathbf{3 6}][\mathbf{3 7}][\mathbf{3 8}]$.

For Mo and $\mathrm{W}$ in the group 6 , the monocarbide $\left(M \mathrm{C}_{x}\right)$ are thermodynamically stable at low temperature when their metal atoms are packed in simple hexagon with nearly full occupancy of $\mathrm{C}$ atoms in the center of trigonal prism interstitial sites, e.g. WC and $\gamma$-MoC (space group $P \overline{6} m 2$ ). A reduced stability of $\gamma$-MoC phase by increasing the $\mathrm{C}$-vacancy has been theoretically demonstrated by Hugosson et al. In addition to the rock-salt cubic phases $\left(\gamma-\mathrm{WC}_{x} \text { and } \delta \text {-MoC }\right)^{2}$ discussed previously, at least two more $\mathrm{MoC}_{x}$ phases have been reported. One is also a high temperature phase, denoted as $\eta$-MoC $x$, while the other is a metastable phase, $\gamma^{\prime}-\mathrm{MoC}_{x}$, which can be further stabilized by oxygen inclusion. In the latter two structures, the $\mathrm{C}$ atoms are distributed both octahedral and trigonal prism interstitial sites [39] [40].

The group 5 transition elements and Mo and $\mathrm{W}$ in the group 6 can also form $M_{2} \mathrm{C}_{x}$ carbide, which is a hexagonal close-packed sublattice of metal atoms with $1 / 2$ occupancy of $\mathrm{C}$ atoms in the octahedral interstitial sites. At least two modifications of $M_{2} \mathrm{C}_{x}$ are formed due to ordered/disordered arrangement of $\mathrm{C}$ atoms in the structures at different temperatures. For example, the $\beta-\mathrm{Mo}_{2} \mathrm{C}_{x}$ and $\beta-\mathrm{W}_{2} \mathrm{C}_{x}$ (space group $P 6_{3} / m m c$ ) is a high temperature phase where the interstitial sites are randomly occupied by $\mathrm{C}$ atoms, while the $\alpha-\mathrm{Mo}_{2} \mathrm{C}_{x}$ and $\beta^{\prime}-\mathrm{W}_{2} \mathrm{C}_{x}$ (space group $P b c n, \zeta-$ $\mathrm{Fe}_{2} \mathrm{~N}$ type) exists in lower temperature with an ordered distribution in the basal planes of carbon. Additional modifications, such as $\beta^{\prime \prime}-\mathrm{W}_{2} \mathrm{C}_{x}$ and $\varepsilon-\mathrm{W}_{2} \mathrm{C}_{x}$, have been reviewed with different $\mathrm{C}$ atom distributions in the anti-CdI 2 type and $\varepsilon-\mathrm{Fe}_{2} \mathrm{~N}$ type, respectively [39] [40].

\subsection{Ternary Transition-Metal Carbides}

Research on ternary TMC phase diagrams is triggered by interactions of applied TMCs with surrounding materials, such as diffusion barriers [41] [42], composites [43], and other applications with existence of oxygen [44] [45], as well as by the needs of improvements. The ternary (or higher order) TMCs can either be solid solutions, where atoms of original system are substituted by a third element, or ordered phases, where atoms of a third element join the crystal structure with a spatial periodicity. 
Solid solutions at the non-metal site, i.e. substitution on C site, commonly occurs with elements in the same period around $\mathrm{C}$, such as $\mathrm{B}, \mathrm{N}$ and $\mathrm{O}$. These elements have similar atomic size with $\mathrm{C}$, which allows $\mathrm{C}$-substitution in the interstitial sites of metal atoms, and they usually can have high, even full, ratio of carbon substitution, forming iso-structure borides, nitrides or oxides. Titanium carbonitride, $\mathrm{Ti}(\mathrm{C}, \mathrm{N})$, is an early example of a ternary TMC formed by solid solution of TiC and TiN, providing better high temperature hardness and oxidation resistance than $\mathrm{TiC}$ alone [46].

In addition, solid solutions with two transition metal species exist in many ternary systems, and they are mostly studied for improved mechanical performances as carbide composites or coatings, for example $(\mathrm{Mo}, \mathrm{W})_{2} \mathrm{C}$ [13] [47]. In some systems where the mutual solubility of two transition metal species are low, the minority phase can hinder the growth and reduce the grain size of the majority phase, providing extra material hardening, for example in $\mathrm{W}-\mathrm{V}-\mathrm{C}$ and $\mathrm{W}-\mathrm{Cr}-\mathrm{C}$ systems [48].

On the other hand, ordered phases are formed in ternary TMC systems with an element from group 13-17 or another transition metal [13] [49], where they are mostly studied with $\mathrm{Al}$ and $\mathrm{Si}$ as the third element. The ternary TMC with $\mathrm{Al}$ and $\mathrm{Si}$ are usually reported with enhanced oxidation resistance due to formation of denser alumina and silica products compared to transition metal oxides, preventing further oxygen penetration. Nevertheless, very few ternary TMC has been put into practical application since they are generally very brittle. Some commonly encountered phases of this type are $M_{3} \mathrm{AlC}$ (also known as inverse perovskite structure), $M_{3} \mathrm{Al}_{2} \mathrm{C}, M_{5} \mathrm{Al}_{3} \mathrm{C}$ and $M_{5} \mathrm{Si}_{3} \mathrm{C}$ for $M$ elements commonly from group 3-6. In above phases, similar $M_{6} \mathrm{C}$ octahedrons with interstitial $\mathrm{C}$ atoms are formed, and the structure is built by different stacking of the octahedrons and atoms of the third element [50].

\subsection{Inherently Nanolaminated Carbides}

Some of the ternary TMCs are identified with ordered repetition of crystalline layers along one crystal axis and they are sometimes described as inherently nanolaminated phases. The term inherently indicates that the nanolaminated structures of these carbides are not only thermodynamically stable or metastable, but also spontaneously ordered themselves into layered structure at the occurrence of the phases. Artificial nanostructures are not included as inherently nanolaminated phases because these phases do not necessarily form in layered structures, though they can still be thermodynamically stable [16]. 
The $M_{n+1} A X_{n}$ (or MAX phases, space group $P 6_{3} / m m c$ ), where $M$ is a group 3-7 transition metal, $A$ is commonly a group 13-14 element, $X$ is $\mathrm{C}$ or $\mathrm{N}$ and $\mathrm{n}$ is an integer between 1-3, are a group of nanolaminated phases with layers of transition-metal carbides or nitrides interleaved by $A$ elements. The carbide and nitride layers are formed by edge-sharing $M_{6} X$ octahedrons, which is identical to the binary carbides in the rock-salt structure, while the $A$ atoms are located at the center of trigonal prisms between the two twinned layers of the octahedrons. By increasing the $n$ number, the total number of $X$ layers between two $A$ layers increases respectively, i.e. one $X$ layer for $n=1$; two for $n=2$; three for $n=3$, and therefore the size of the unit cell increases, as shown in Figure 2-2 [15]. To date, the carbide phases are still the majority of the entire 70+ MAX phase members, growing in numbers with new $M-A-X$ combinations, with partial substitutions (solid solution) on $M, A$, and $X$ sites, for example $(\mathrm{Ti}, \mathrm{V})_{3} \mathrm{AlC}_{2},(\mathrm{Nb}, \mathrm{V})_{2} \mathrm{AlC},(\mathrm{Nb}, \mathrm{V})_{4} \mathrm{AlC}_{3},(\mathrm{Nb}, \mathrm{Zr})_{2} \mathrm{AlC}$ [51], $(\mathrm{Cr}, \mathrm{Mn})_{2} \mathrm{AlC}$ [52], $\mathrm{V}_{2}(\mathrm{Ga}, \mathrm{Al}) \mathrm{C}[\mathbf{5 3}]$ and $\mathrm{Ti} 2 \mathrm{Al}(\mathrm{C}, \mathrm{N})[\mathbf{5 4}]$ and with ordered quaternary nanolaminates, for example in Cr-Ti-Al-C [55], Cr-V-Al-C [56] and Mo-Ti-Al-C [57] systems.
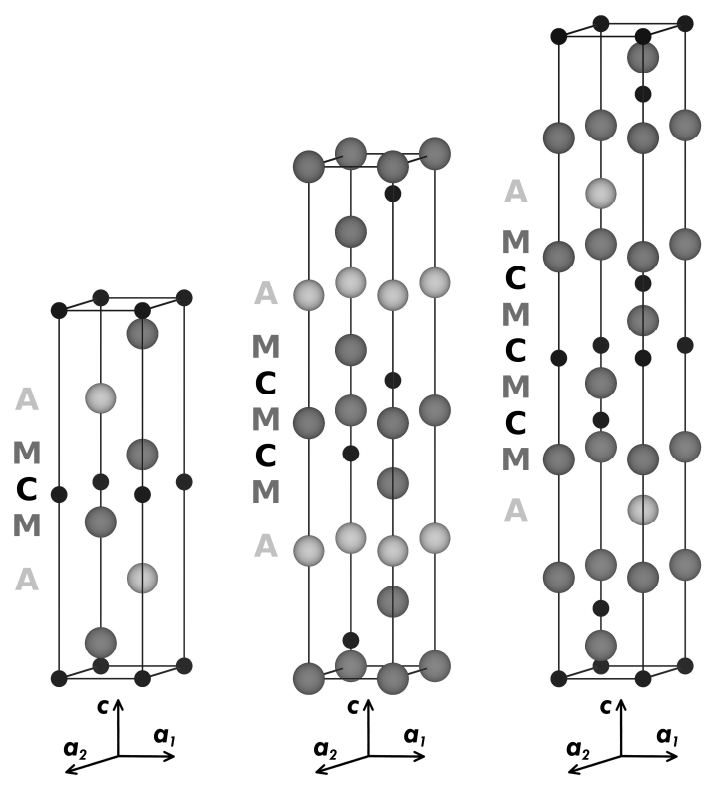

Figure 2-2. Three types of $M_{n+1} A \mathrm{C}_{n}$ (MAX) phases with $n=1$ (left), 2 (center) and 3 (right). Some layers are labelled with different elements ( $M, A$ and $\mathrm{C})$. 
Compared to MAX phases, the $M_{n} \mathrm{Al}_{3} \mathrm{C}_{n+2}$ and $M_{n} \mathrm{Al}_{4} \mathrm{C}_{n+3}$ phases, where $n=2,3,4$ and $M=\mathrm{Zr}$ and $\mathrm{Hf}$, have $\mathrm{Al}_{3} \mathrm{C}_{2}$ and $\mathrm{Al}_{4} \mathrm{C}_{3}$ layers, respectively, between two $(M C)_{n}$ layers instead of pure $A$ layer, see Figure 2-3 [58] [59]. Hence, the metallic bonding sequence $M-A$ in the MAX phases is here replaced by a more covalent-ionic bonding sequence $M$-C-Al [60]. The structures of $\mathrm{Al}_{3} \mathrm{C}_{2}$ and
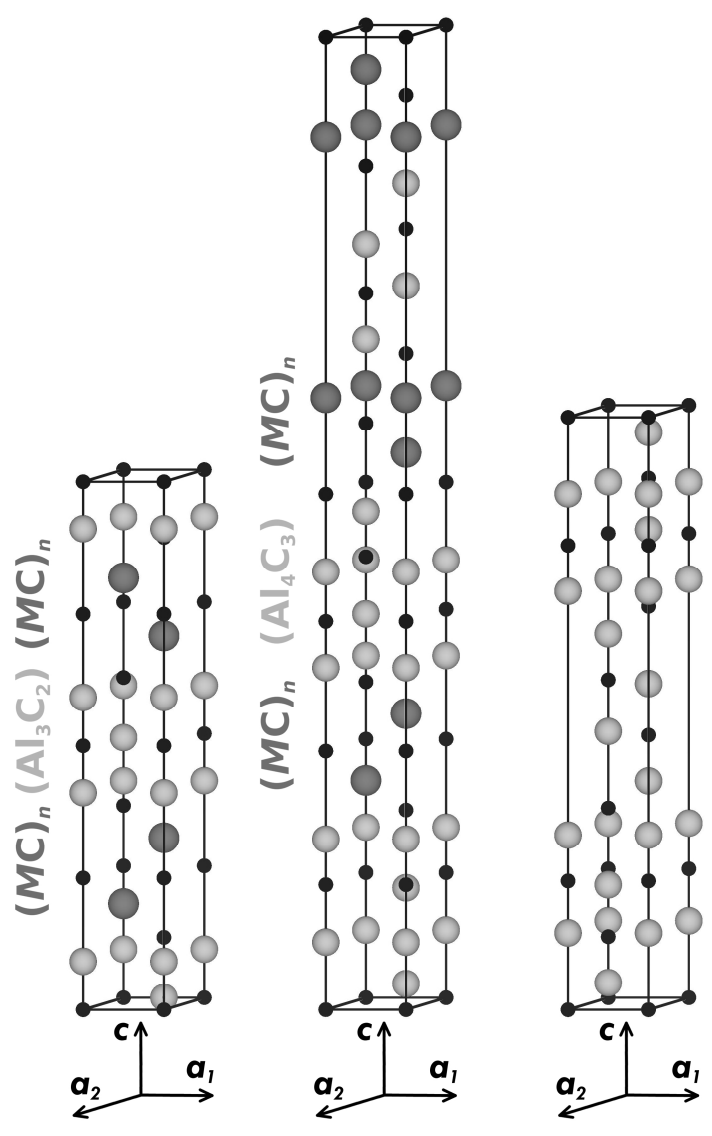

Figure 2-3. Illustrations of $M_{n} \mathrm{Al}_{3} \mathrm{C}_{n+2}$ (left) and $M_{n} \mathrm{Al}_{4} \mathrm{C}_{n+3}$ (center) nanolaminated carbides with $n=2$, assigned to space group $186\left(\mathrm{PG}_{3} \mathrm{mc}\right)$ and $160(R 3 m)$ according to Ref. [26] and [58]. The crystal structure of $\mathrm{Al}_{4} \mathrm{C}_{3}$ (right) is given to show the similarity with above phases. 
$\mathrm{Al}_{4} \mathrm{C}_{3}$ layers are actually analogue to the structure of $\mathrm{Al}_{4} \mathrm{C}_{3}$ phase (space group $R \overline{3} \mathrm{~m}$ ), while the $(M C)_{n}$ layers are structured similarly as in MAX phases [61]. The $M \mathrm{Al}_{3} \mathrm{C}_{3}$ and $M \mathrm{Al}_{4} \mathrm{C}_{4}$ phases, i.e. $n=1$, are different from the other members by the fact that the $M \mathrm{Al}_{3} \mathrm{C}_{3}$ has only been experimentally discovered with $M$ is a group 3 transition element or inner transition element (e.g. $\mathrm{ScAl}_{3} \mathrm{C}_{3}$ [61], $\mathrm{YAl}_{3} \mathrm{C}_{3}[58], \mathrm{UAl}_{3} \mathrm{C}_{3}$ and $\mathrm{YbAl}_{3} \mathrm{C}_{3}$ [62]) and $\mathrm{MAl}_{4} \mathrm{C}_{4}$ was only identified in a different space group $P 3 m 1$ where $M=\mathrm{Zr}$ and $\mathrm{Hf}$ [63] [64]. Interestingly, so far these nanolaminated phases with Al-C layers and the MAX phases do not overlap in the same material system $M-A-\mathrm{C}$, for example MAX phase in $\mathrm{Zr}-\mathrm{Al}-\mathrm{C}$ system has neither been reported, nor Al-C nanolamiated phase in Ti-Al-C system.

Other examples of nanolaminated ternary carbides are $\mathrm{Mo}_{2} \mathrm{Ga}_{2} \mathrm{C}$ and $\mathrm{Mo}_{2} \mathrm{BC}$ phases, with different stacking of $A$ layers and/or the $M C_{6}$ octahedrons, see Figure 2-4 [65] [66] [67]. The former, i.e. $\mathrm{Mo}_{2} \mathrm{Ga}_{2} \mathrm{C}$, is a new nanolaminated carbide first time discovered in this work, see Paper I. It has a
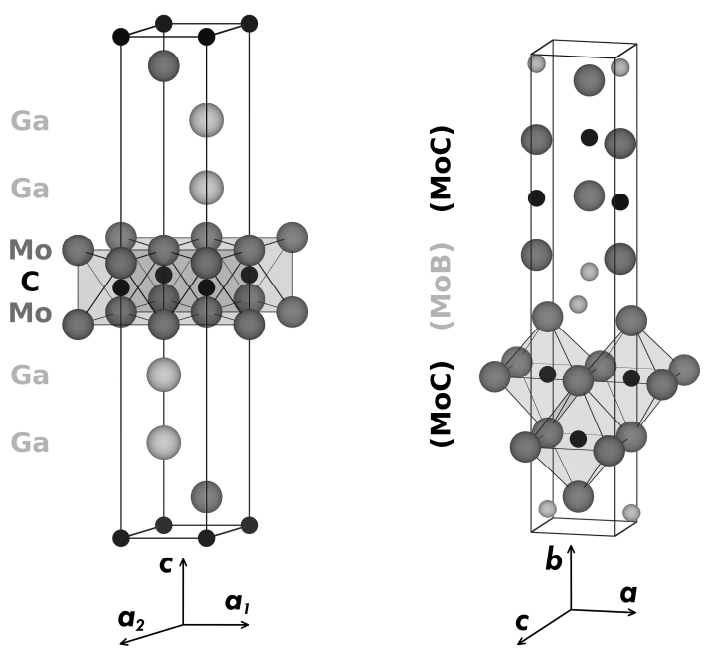

Figure 2-4. Illustrations of $\mathrm{Mo}_{2} \mathrm{Ga}_{2} \mathrm{C}$ (left) and $\mathrm{Mo}_{2} \mathrm{BC}$ (right) nanolaminated carbides. Some $M_{6} \mathrm{C}$ octahedrons in each phase are indicated with $\mathrm{C}$ atoms in their centers. 
doubled atomic layer of $A$ element in an ordinary structure of MAX phase with $n=1$, and is determined to have very close relations with MAX phases, structurally and chemically, in Paper II.

Though nanolaminated ternary TMCs are quite different from each other in term of structure and bonding, they generally exhibit larger damage tolerance and higher machinability, but lower hardness, compared to their $M$-C binary counterparts. This is related to the laminated structure, which allows easier basal plane slip, delamination and formation of kink bands, and has been demonstrated by $\mathrm{Ti}_{3} \mathrm{SiC}_{2}$ and $\mathrm{Ti}_{2} \mathrm{AlC}$ systems [68] [69] [70] [71] [72]. This provides the nanolaminated carbides moderate ductility, compared to most ceramics that are extremely brittle, in addition to the high stiffness and strength from the ceramic nature. 


\section{Thin Film Synthesis}

A thin film is a layer of material with of few atomic layers up to few micrometers in thickness, depending on the scope of application or analysis. It is an important method to modify the existing properties at the surface of another underlying material, which is called a substrate. Various kinds of products can, therefore, be fabricated with combined properties by coating thin films on top of substrates, such as a light-weighted plastic-ware decoratively coated with a metal thin film, or a metallic structural material coated with a chemically inert ceramic film. In some applications, multiple thin films can be stacked on top of each other, for example in electronic and optical devices, where multi-layer coatings are done in regular basis.

\subsection{Physical Vapor Deposition}

Thin films can be applied through various deposition techniques, where the starting materials are delivered from sources on to substrates in different forms, for example plasma and/or neutral molecules as in vapor deposition, ions as in electrochemical plating, molten states as in thermal spray or solutions (normally with volatile solutes) as in spin coating. The choice of the most suitable process is very much depending on limitations and requirements of the final product, for example temperature tolerance, impurity level, thickness and uniformity [73].

Vapor deposition involves two major classes of deposition techniques, namely physical vapor deposition (PVD) and chemical vapor deposition (CVD). CVD relies on chemical reactions of the starting materials (the precursors) taking places on substrate surface, where the products will either 
condensed as thin films or be evacuated from the system [74]. PVD processes, on the other hand, have no chemical reactions involved in the main deposition mechanism, where the materials are vaporized from the sources (or the targets) and directly condensed on substrate surface as thin films. Therefore, PVD processes are less limited by generation of chemical by-products and thermal equilibrium. In practice, they are commonly employed for depositing thin films with low impurity level and/or thermodynamically metastable phases [73].

On the other hand, the 'reaction-less' condensation also sets a limitation to PVD processes, compared to CVD processes, that the efficiency of deposition (or the deposition rate) is significantly reduced when a substrate is not in the 'line-of-sight' of the target. Hence, depositions on complex-shaped substrates are usually challenging for PVD processes, which can be seen from the differences of microstructure, density and growth rate from on-axis and off-axis deposited thin films [75]. In the following subsections, brief introduction is presented for the PVD methods used in this work, namely the direct current magnetron sputtering and the pulsed cathodic arc deposition processes.

\subsubsection{Direct current magnetron sputtering}

The magnetron sputtering process is normally initiated with ionization of gas molecules inside the system by accelerating electrons with a negative bias (in order of $10^{2}-10^{3} \mathrm{~V}$ ) on the target surface. The energized electrons can consequently ionize gas molecules via collisions under certain probability. Due to the target bias, the positive ions from the ionization are accelerated toward, and eventually collide with, the target surface. The incident ions transfer the momentum and the energy to the target material, creating series of collisions, or collision cascades, between target atoms. Such collision cascades may return part of the momentum and the energy back to the surface, causing surface atoms or molecules to be ejected from the surface. The above process of removing materials from a surface by ballistic impingement of energetic particles is referred to as sputtering. Thereafter, deposition process begins when the ejected target species come to the substrate surface, nucleate and grow into a thin film [76]. See Figure 3-1 for a brief illustration of the sputtering process on a surface.

In order to reduce the impurity level in thin films, the deposition system is normally evacuated (below $10^{-4} \mathrm{~Pa}$ ) to reduce impurity incorporation and filled in with sputtering gas to a certain working pressure (in order of $10^{-1}-10^{0} \mathrm{~Pa}$ ) during a deposition. The sputtering gas molecules will 


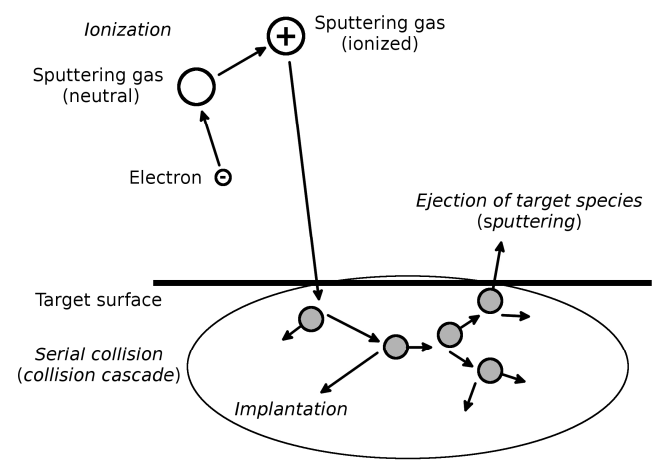

Figure 3-1. An illustration of a sputtering process: ionization (up-left), impingement (center-left), collision cascade (bottom) and ejection of target species (center-right). The objects in the figure are given in regular fonts, and the events are in italic fonts.

be ionized to create plasma as the main source of the positive ions in the sputtering process. Hence, such gas species is ideal to be easily ionized (with a low ionization energy) and chemically inert to reduce unwanted chemical reactions [76]. Today, $\operatorname{argon}(\mathrm{Ar})$ is the most popular sputtering gas due to an optimal combination of its abundance, ionization energy and similar atomic mass compared to the common depositing materials (period 2 - 4). Other noble gas species, e.g. neon $(\mathrm{Ne})$ and krypton (Kr), and mixtures of above gas species can also be utilized in sputtering deposition processes [77] [78].

The emission of secondary electrons from the target surface sputtering are the most important effect on sustaining the sputtering deposition process. On the contrary to the positive ions, the emitted secondary electron are expelled away from the target by the negative bias, and they can consequently ionize or excite the gas molecules upon collision. The ionized or excited gas molecules can further complete the cycle by creating positive ions for the sputtering deposition and the secondary electron emission [76]. However, without sufficient confinement to the electrons, a diode sputtering process usually has a low ionization efficiency of the sputtering gas, where a high 
target bias is constantly required to sustain the process. Moreover, the electrons expelled by the high voltage can easily reach the substrate, causing unwanted heat damage to the substrate and even the deposited film [79].

Therefore, magnetron sputtering process solves the problems in diode sputtering by confining electrons close to the target with a magnetic field. The magnetic field is commonly applied by permanent magnets placed behind a planar target like in this work, but it can also be done by many other ways, such as an electromagnetic coil surrounding a cylindrical target [80], see Figure 3-2. With the confinement, the electrons has prolonged trajectories and increased collision events before they escape and lose to an anode. The densified plasma above the cathode can increase the sputtering rate of the target and the deposition rate on the substrate compared to a diode sputtering deposition process. Moreover, since the secondary electron emission is more efficient in such confinement, the applied voltage on the target is normally lower compared to diode sputtering in a constant power operation [79].
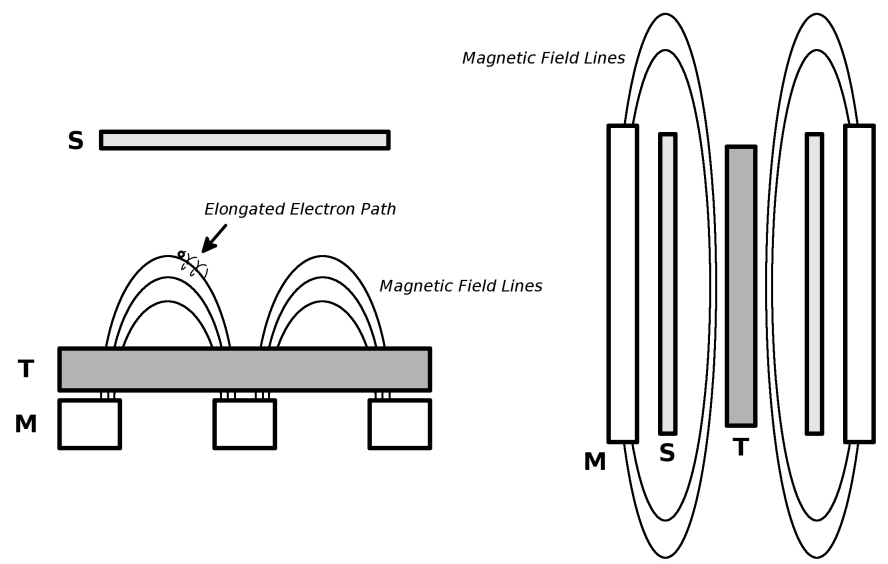

Figure 3-2. Illustrations of magnetron sputtering deposition processes with (left) a planar target and (right) a cylindrical target. $\mathrm{M}$ stands for magnets, $\mathrm{T}$ for targets and $\mathrm{S}$ for substrates. 
Last, the term direct current is used in contrast with a pulsed magnetron sputtering process, where in the latter case the amplitude of target voltage is pulsed instead of constant as in direct current magnetron sputtering (DCMS). The pulsed process allows higher peak power on the target without risking to melt the target material, and for example in high-power impulse magnetron sputtering (HiPIMS) process an ionization degree above $90 \%$ for the ejected species can be achieved, compared to less than $10 \%$ in DCMS [81]. The effect of ionization degree on deposited films will be elaborated in Section III.2.

\subsubsection{Pulsed cathodic arc}

In a cathodic arc process, the target material generates plasma in a cathodic arc discharge on the surface of a negatively biased targets (as cathode). Cathodic arc together with thermionic arc are two types of collective electron emission processes, or arc discharges, where electrons are emitted in certain areas called cathode spots when a certain condition is fulfilled. This is very different from individual electron emission processes, e.g. glow discharge and sputtering, where emission yield (the number of electron emitted divided by the number of incident particle) can be applied. In thermionic arc discharge, a surface is heated until electrons are sufficiently thermalized to overcome the working potential of the surface material and escape into vacuum. On the other hand, an electric field generated locally in cathodic arc discharge allows the surface electrons to overcome the potential via quantum-tunneling at the places with lower work function or higher electric field locally $[\mathbf{8 2}][\mathbf{8 3}]$.

During arcing, high density of electrons (in order of $10^{12} \mathrm{~A} / \mathrm{m}^{2}$ ) are emitted from each of multiple $\mu \mathrm{m}$-sized cathode spots, where the target materials at the surface are resistively heated up by such high flow of electrons. For metal targets, the raised temperature at the cathode spots has positive effects to further increase the thermionic electron emission and the local electric resistivity, which in return increase the temperature again. Consequently, the local temperature can reach several thousands of $\mathrm{K}$ in a time frame of few ns before a cathode spot extinct (after few tens of ns), and such temperature is high enough to transform almost all metals into the plasma state at the emission center [84]. Such rapid transformation in a very confine volume pushes the plasma fiercely away from the target surface into the vacuum with supersonic ion velocities (in order of $10^{3}-10^{4} \mathrm{~m} / \mathrm{s}$ ). The plasma can then travel through the system and reach the substrate with a higher direct ion 
kinetic energy (ranging from $20-160 \mathrm{eV}$ ) and a nearly $100 \%$ ionization degree, compared to DCMS (often less than $10 \mathrm{eV}$, with almost all neutral atoms) [85] [86].

As mentioned above, the ignition of cathodic arc discharge requires a sufficiently high electric field, at least locally, across a cathode and an anode. In modern cathodic arc deposition processes this done by various triggering methods, where the arc is first initiated by an auxiliary triggering component [86]. For example in mechanically drawn arc a triggering electrode is repeatedly connecting and disconnecting against the target surface, where it increases the electric field by shortening the distance between the electrodes. Another method is utilizing focused laser beam to locally increase the temperature on the target surface and, hence, trigger cathodic arc via thermionic arc discharge. In Paper III, the arc was ignited by a triggering method involving a surface voltage flashover, where the arc can be more easily established between the cathode and the triggering electrode through surface states of an insulating surface. See Figure 3-3 for an illustration of the cathode used in this work, and see Ref. [87] for more detailed descriptions for the system.

The arc process can further be used in DC mode and pulsed mode, where in DC mode the bias on all components are constant compared to pulsed bias on the trigger and the target in pulsed mode (the anode are normally grounded). The DC arc deposition is often found in industry since dense

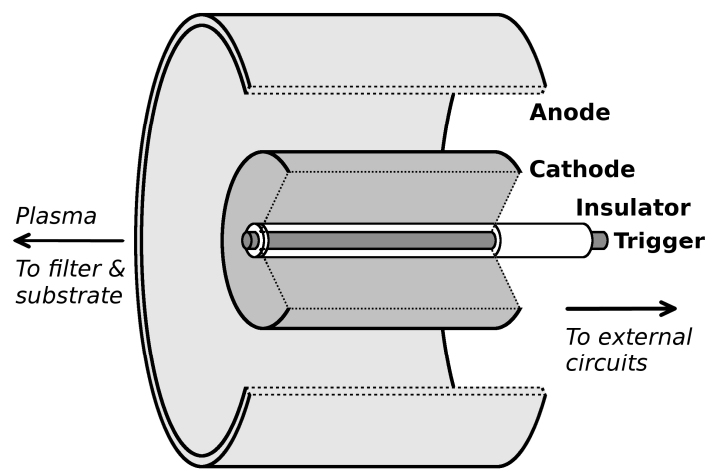

Figure 3-3. An illustration of the cathodic arc source used in Paper III, where the arc is initiated by a surface voltage flashover between a centered trigger pin and surface of the cathode. Part of the anode, the cathode and the insulator are removed (dotted lines) for better view of the interior structure. 
films with good to excellent adhesion can be normally be deposited at high deposition rate. The pulsed cathodic arc deposition, on the other hand, is often found in small-scale and laboratorysized system, where a wide range of research can be done with extra controls to deposition parameters, e.g. frequency, pulse length, composition. For example, in pulsed cathodic arc process higher peak currents (close to or more than $1 \mathrm{kA}$ ) can be achieved compared to DC process (normally less than $0.5 \mathrm{kA}$ ) because of better cathode spot stability and less target-cooling limitation [88] [89]. In addition, the pulsed arc allows better controls on the plasma composition by adjusting the numbers of pulses ignited from multiple targets of different materials.

However, cathodic arc deposition processes have an inherent disadvantage on inclusion of target material clusters of nanometer and micrometer-size in deposited films, whose compositional and structural homogeneity can be largely but locally affected. These clusters are often referred as macroparticles or 'droplets', and in fact they have a continuous size distribution from single atom/ion (the plasma) up to particles of micrometers. The formation of droplets is hypothetically explained by molten target materials around an emission center (roughly the center of a cathode spot) being pushed out by the force of the ejected plasma. Though removal of droplets is not necessary for all types of products, but is often a complicated and costly issue when droplets are unwanted since a filter often causes significant reduction in deposition rate and possibly an extra power consumption. Nonetheless, a droplet filter can be installed between targets and substrates, working either to enhance the plasma-to-droplet ratio or to remove majority of droplets from the plasma [90]. In Paper III, a 90 $0^{\circ}$-bent solenoid, installed between the pulsed cathodic arc source and substrates, was used as a magnetic macroparticle filter during depositions, as shown in Figure 3-4.

\subsection{Thin film growth}

Growth stage of a thin film is refer to, in the scale of time, events after target species arrive a substrate and until the entire deposition finishes. In other words, thin film growth bridges deposition parameters to properties of a final thin film product, where studying in the growth of films not only helps in achieving certain properties, but also in developing fundamental material science, e.g. tendencies in the periodic table.

The growth mechanism of thin films is based on the chemical thermodynamics, where the difference of the system's free energy from the chemical thermodynamic equilibrium provides the driving force for deposited atoms (adatoms) to diffuse and to stay at the original sites. Hence, the 


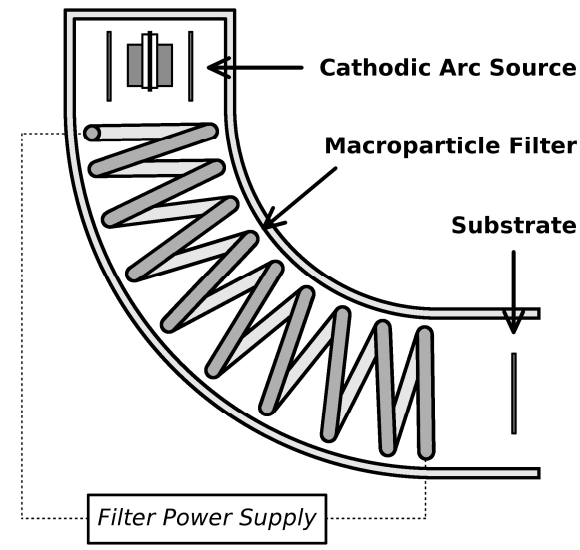

Figure 3-4. An illustration of the arrangement for the cathodic arc source, the macroparticle filter and the substrate in Paper III. For simplicity, only one cathode and only a 9-turn solenoid are shown in the figure. Dotted lines indicate electrical connections from the filter to the filter power supply.

adatoms adjust their chemical bonding conditions to lower the free energy of the system under a given set of composition, temperature and pressure. Consequently, when the driving force is large enough to mobilize adatoms, a certain combination of stable phases and various microstructure can be formed.

The so-called three primary growth modes, sorted by Bauer [91], illustrate simplified formation of microstructures where adatoms of a single species grow with weaker or stronger interactions with hetero-atoms (substrate atoms) and with itself (adatoms), see Figure 3-5. Consequently, the system lowers its chemical potential by diffusing adatoms into positions where weak interactions can be minimized. That is, for a crystallized film material, it exhibits a certain bonding relation with its underlying substrate (e.g. textured growth), and it grows only in certain crystal plane to expose surfaces with lowest surface energy (e.g. (111) plane in FCC crystal).

However in a condition where the local system is metastable and the local chemical potential is close to the equilibrium of a larger system, the driving force might not be enough for any diffusion or for long-range diffusions, e.g. to diffuse across the substrate surface. Hence, the thermodynamic 


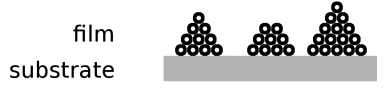

(a)

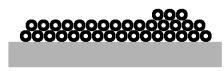

(b)

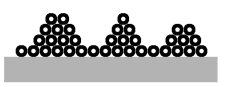

(c)

Figure 3-5. Illustrations of the three primary growth modes: (a) Volmer-Weber (island) growth (b) Frank-van der Merwe (layer-by-layer) growth and (c) Stranski-Krastanov (layer-into-island) growth.

equilibrium cannot be achieved in this diffusion-limited condition, and instead, metastable phases and corresponding microstructures can be grown. For example, cubic (Ti,Al)N solid solution, whose stable condition is separated cubic TiN plus hexagonal AlN phases, can be deposited [92]. At the same time, microstructures such as reduced grain size and under-densed (porous) films can be introduced, see Figure 3-6, and the three primary modes might not be sufficient to describe such lower mobility cases $[\mathbf{9 3}]$.

In order to suppress the metastable competing phases and/or the microstructures grown in the low mobility condition, additional energy flux can be supplied to the substrate surface, providing extra kinetic energy to activate diffusions. Commonly, the additional energy is provided by increasing growth temperature or by enhancing incident ion energy [93]. The former, i.e. changing temperature, can also lead to changes of the equilibrium condition, making it is sometimes a 'difficult' parameter to optimize. However if a desired phase has large equilibrium range, effects

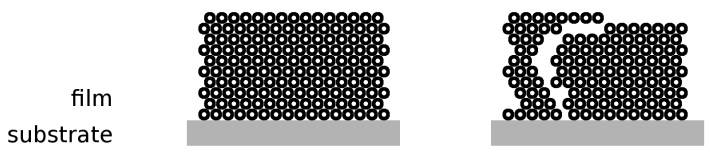

Figure 3-6. An illustration of an ideal layer-by-layer growth (left) and a possible porous microstructure introduced by diffusion limited growth (right), where an incomplete and under-dense first atomic layer is shown. 
of depositing denser films with larger grain size can normally be observed at higher growth temperature.

On the other hand, increasing incident ion energy increases the adatom mobility by transferring kinetic energy through collision cascades (as in sputtering), which not only mobilize surface diffusions but also introduce short ranges mixing in the growth direction. Energizing incident species is normally done by applying a negative or positive bias on a substrate to accelerate or to decelerate the ions, respectively [94]. This is one reason for developing various PVD processes with highly ionized target species, such as cathodic arc deposition and HiPIMS, to maximize the control over incident ions [95] [96]. In DCMS processes, where the ionization degree of target species is low, the type II unbalanced magnetron with weaker electron (and plasma) confinement can be utilized to enhance the sputtering gas ion bombardment on the substrate [79].

To illustrate the impact of adatom mobility on the microstructure of the deposited films, the structure zone diagram (SZD) is a simplified empirical model that helps in understanding the growth condition in a conceptual way. In the SZD modified and published by Anders, it shows different microstructure evolutions by varying the adatom mobility through the growth temperature and the incident ion energy [97]. This is explained by ion bombardment introduced extra defects and ion implantation (e.g. sputtering gas), which cause disruption of crystal growth and reduction of grain size. Moreover, the deposition rate decreases when increasing incident ion energy due to re-sputtering on the deposited film, which eventually leads to erosion and a negative deposition rate when the ion energy is too high. 


\section{Thin Film Characterization Techniques}

\subsection{Structural analysis techniques}

\subsubsection{X-ray diffractometry}

$\mathrm{X}$-ray diffractometry (XRD) is a technique where information about a sample is collected from analysis of diffraction events between incident X-ray and sampled materials. It is an efficient method to qualitatively examine the phase composition and the structural information of crystalline samples, since it generally requires no complex sample preparation, no vacuum systems, and is able to be integrated for experiments in non-ambient pressure and temperature. With the help of Rietveld analysis (or Rietveld refinement), where measured diffraction patterns are fitted and compared with theoretical patterns of built models, quantitative phase and structural information can also be obtained from powder samples. See Paper I and II where Rietveld analysis were done on XRD and neutron diffraction patterns of $\mathrm{Mo}_{2} \mathrm{Ga}_{2} \mathrm{C}$ powder samples.

The X-ray diffraction comes from the elastic scattering of the incident electromagnetic wave and mainly the electrons surrounding the sample atoms. The scattering X-ray has the same wavelength $\lambda$ as the incident $\mathrm{X}$-ray and are in phase after scattering from the atoms. When the X-ray scattered from different sources (atoms) interferes, a diffraction pattern is created with angularly distributed photon intensity, $I(2 \theta)$, on the scattering plane, i.e. the plane where the photon source, the scattering event and the observer (the detector) are sitting on. The argument $\theta$ is referred to as scattering angle, 
and is specified as half of the angle between the incident and the scattering X-ray path, see Figure 4-1.

Bragg's condition describes the condition where an $n$-th constructive interference occurs for a group of periodic crystal planes with interplanar spacing $d$,

$$
2 \cdot d \cdot \sin \theta=n \cdot \lambda
$$

Notice that usually $n=1$ the most intense diffraction is the only one visible, and $d$ is a spacing lying in the scattering plane and perpendicular to the zero beam axis (the incident path when $\theta=$ 0 ). Beside the diffraction condition, the intensity of a diffraction pattern can also be affected by many sample characteristics, such as the structure factor and the atomic form factor of a sample. For example in Paper I, carbon has too low atomic form factor to contribute substantially to the XRD patterns, which are mostly contributed by the structure of the heavy elements (Mo and Ga).

Hence, a crystalline phase can have its own unique XRD pattern, where $2 \theta$ positions fulfilling all above conditions have higher intensity and form peaks from the background. A diffraction pattern from a sample with multiple crystalline phases will be a superposition of the two individual diffraction patterns. Therefore, a collection of many diffraction data, e.g. a database, can be used to identify the phase composition from an acquired XRD pattern.

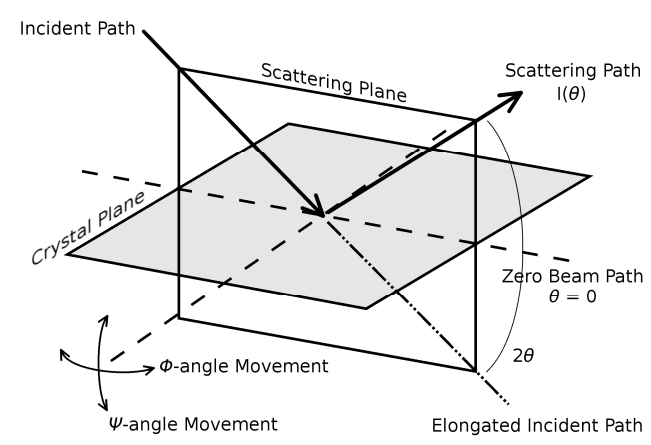

Figure 4-1. An illustration of the XRD geometry. 
In practice, the sample can also be measured with different angles with respect to its original angular position, where the resulting diffraction patterns can provide information such as texture (of crystalline thin films) and symmetry of crystals. See the XRD pole figures in Paper I and the $I(\Phi)$ plots with given $\Psi$ tilts in Paper III for examples.

\subsubsection{Transmission electron microscopy}

Transmission electron microscopy (TEM) is a delicate study of micrographs, utilizing interactions between incident electrons and sampling materials, which is somewhat analogous to the photonmaterial interaction used in optical microscope. The main advantage of using electrons as imaging source is to obtain higher resolution with shorter wavelength of the source, which is related to the kinetic energy of electrons and, therefore, to the accelerating voltage of the source.

For example, an electron source with $200 \mathrm{kV}$ acceleration, which is generally used in TEM, can create electrons with wavelength less than $3 \mathrm{pm}$, which is about 5 order less than the lower limit (say, $300 \mathrm{~nm}$ ) of visible light. The very high energy electron source used in TEM allows acquiring micro- and nanometer scale images, electron diffraction patterns, as well as collecting possible electron or photon emission from the specimen, see Figure 4-2, which is not feasible in normal optical microscopy. However, such high voltage electron source also makes the technique more costly (in terms of finance and time) and more restrictive compared to many other analytical methods.

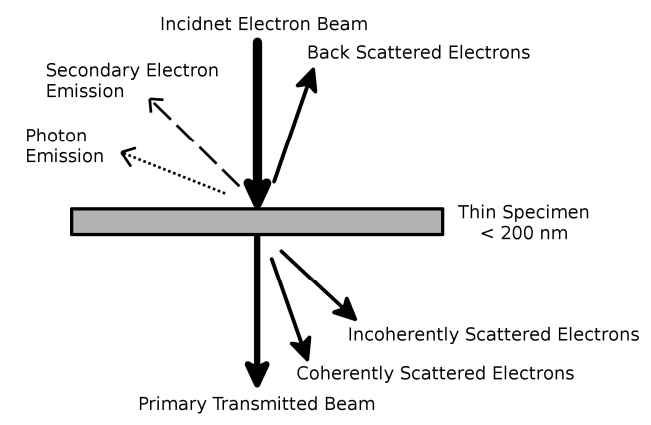

Figure 4-2. Possible interactions between an electron beam with materials irradiated by former. 
TEM imaging relies on the intensity contrast created by electrons transmitted through a very thin specimen (normally less than $200 \mathrm{~nm}$ ). In a TEM image, the contrast can be caused by difference of multiple properties in the region of interest (ROI), such as crystal structure, specimen thickness, chemical composition, which diffract, absorb and scatter electrons differently. Since all contrast mechanisms can add up at the same ROI together (they overlap), one challenge in analyzing TEM images is to identify the origin of the contrast in order to obtain useful information.

Besides micrographs, diffraction patterns, formed by elastically scattered electrons, can be obtained at the back focal plane of the object lens in TEM. It is common to use an extra aperture to select the ROI to take the diffraction pattern, and therefore this technique is also referred to as selected area electron diffraction (SAED). The SAED patterns contain structural information of the specimen in two dimensions that helps in interpretation of crystal symmetry.

High resolution TEM (HR-TEM) is one specialized TEM operation in which nanometer scale and possibly atomic scale images can be obtained in a better optimized condition compared to normal TEM. The HR-TEM imaging forms mainly by the phase contrast, in which it assumes the incident electrons are coherent and the specimen thickness is small and uniform. Hence ideally, the only contrast observed is due to the different phase shift introduced when incident electrons transmitted through different atomic potentials of the specimen. However, since it is not easy to guarantee all ideal set-ups, addressing one-to-one atomic position still comes very difficult in HR-TEM. In Paper III, one HR-TEM image is shown to compare with the periodic interplanar spacing observed in the XRD pattern of the same thin film sample, which is then assigned to $\mathrm{Zr}_{2} \mathrm{Al}_{3} \mathrm{C}_{4}$ phase.

Another specialized technique is scanning transmission electron microscopy (STEM), in which the incoherently scattered electrons at high scattering angle (the angle between incident path and scattering path) are collected by an annular detector and the direct transmitted beam are left out. It is a different imaging mechanism from normal TEM and HR-TEM, where diffraction (from coherently scattered electrons) plays an important role. The STEM image is, however, mainly affected by the difference in the atomic number and the specimen thickness. Due to the low intensity of the incoherently scattered electrons, STEM utilized a converged beam source, scanning through the ROI, to increase the incoming beam and hence the scattered electron intensities. In an optimal condition, STEM can resolve atomic scale image, as shown in Paper I and II for the Mo and $\mathrm{Ga}$ atomic layers. 


\subsection{Chemical composition analysis}

\subsubsection{Energy dispersive X-ray spectroscopy}

Energy dispersive X-ray spectroscopy (EDS or EDX) is an analytical technique for obtaining information of chemical composition from a measured volume of the sample. It requires an energetic electron beam source to excite the inner shell electrons from the atoms in the sampling volume into vacuum states. When electrons from the outer shells of these atoms decay to the unoccupied inner shell, X-ray photons can be emitted from these transitions (decays).

Such photons possess certain amount of kinetic energy equal to the energy released from the respective transitions, where the transition energy is determined by the electron configuration of each element, i.e. it is characteristic for elements. Hence by acquiring a photon-energy resolved spectrum, qualitative information about the chemical composition can be obtained. If the characteristic X-ray emitting cross-section is taking into account, quantitative analysis can be done for the composition of the sampling volume. Due to smaller cross-sections of X-ray emission for light elements, EDS analysis is normally not suitable for quantifying these elements, especially in EDS detectors with Be-windows.

An EDS detector is often integrated into an electron microscope, including scanning electron microscope (SEM) and TEM, where high energy electron beams (above $5 \mathrm{keV}$ ) are utilized as the excitation sources. This provides a major benefit on acquiring micrographs and chemical information, possibly at the same ROI, in one operating session. Moreover, with an electron beam source that is capable of sweeping the spot of the ROI, e.g. SEM and STEM, a distribution map of chemical composition can be acquired. See Paper I and II for examples, where Mo (in red) and Ga (in green) distributions are shown in the images.

\subsubsection{Time-of-flight elastic recoil detection analysis}

Elastic recoil detection analysis (ERDA) is an ion beam analysis technique, where a sample is irradiated by a mono-energy ion beam to extract information such as chemical composition and elemental depth profile. The incident (primary) ions are commonly ${ }^{35} \mathrm{Cl},{ }^{79} \mathrm{Br},{ }^{127} \mathrm{I},{ }^{63} \mathrm{Cu}$ and ${ }^{197} \mathrm{Au}$ with an incident energy from few tens up to few hundreds MeV. ERDA is capable of detecting and quantifying all elements lighter than incident ion species, and is also possible to detect heavier elements with special detectors. 
The basic principle for ERDA can be explained by the classical kinematics of two-body elastic collision, see Figure 4-3, where the kinetic energy of the recoiled species, $E_{\mathrm{r}}$, after the collision can be described by,

$$
E_{\mathrm{r}}=\left(\frac{4 M_{\mathrm{i}} M_{\mathrm{r}} \cdot \cos ^{2} \beta}{\left(M_{\mathrm{i}}+M_{\mathrm{r}}\right)^{2}}\right) E_{\mathrm{i} 0}
$$

Where $M_{\mathrm{i}}$ and $M_{\mathrm{r}}$ is the mass of the incident ion and the recoiled species, respectively; $E_{\mathrm{i} 0}$ is the initial kinetic energy of the incident ion; $\beta$ is the recoil angle. Given known values for $E_{\mathrm{i} 0}$ and $M_{\mathrm{i}}$ as well as a fixed detection angle $\beta$ to collect recoiled species, $M_{\mathrm{r}}$ can be calculated from Equation (2) with detected $E_{\mathrm{r}}$.

Time-of-flight ERDA (ToF-ERDA) is a setup with two ToF gates before the energy detector in order to measure the velocity of the recoiled species. It is developed to improve the energy resolution for the analysis, since the recoiled energy, $E_{\mathrm{r}}$, can also be determined by several factors other than just Equation (2), such as the roughness of the sample surface, the depth of the recoiled species into the sample and possible multiple scattering (collision) in the sample. However, due to the ToF gates introduced between the sample and the energy detector, the ToF-ERDA usually trades off its detection efficiency for lighter elements.

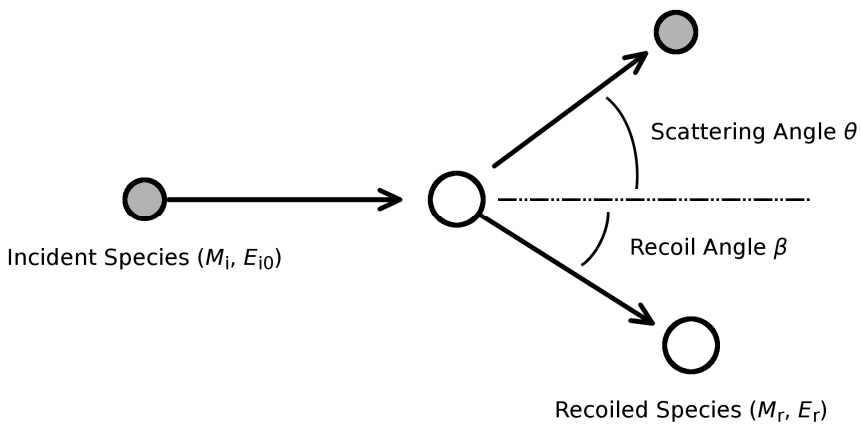

Figure 4-3. An illustration of a two-body elastic collision in the classical kinematics. 


\subsubsection{X-ray photoelectron spectroscopy}

X-ray photoelectron spectroscopy (XPS) an analytical technique which obtains information about the chemical composition and the chemical bonding condition of the atoms in a sample by studying the binding energy of their shell electrons. In XPS, the sample is irradiated by X-ray photons, which can excite the shell electrons from the atoms into vacuum state with certain amount of kinetic energy. Hence, the photon energy, $E_{\mathrm{ph}}$, can be related to the excited electrons' previous binding energy $\left(E_{\mathrm{B}}\right)$ and detected kinetic energy $\left(E_{\mathrm{K}}\right)$ by following equation,

$$
E_{\mathrm{ph}}=E_{\mathrm{B}}+E_{\mathrm{K}}+E_{\mathrm{W} . \mathrm{F} .}
$$

Where $E_{\mathrm{W} . F .}$ is the work function of the detecting material. Given known values of $E_{\mathrm{ph}}$ and $E_{\mathrm{W} . \mathrm{F}}$, $E_{\mathrm{B}}$ of the electrons can therefore be extracted for the reading of $E_{\mathrm{K}}$. Commonly, the XPS read out form the detector is plotted into a spectrum with electron intensity against detected $E_{\mathrm{K}}$ or converted $E_{\mathrm{B}}$. The intensity increases in the spectrum when the corresponding energy position represents a certain shell electron's binding energy. Since the binding energy depends on the electron configuration, which is element-specific, the chemical composition of a sample can qualitatively be interpreted from the peak position of the detected spectrum.

The binding energy of shell electrons can change according to the chemical environment of an atom, i.e. the element or the group bonded to an atom, and therefore a chemical shift can be observed on the respective peak(s). Studying the chemical shift can give additional information about the bonding condition between the elements consisted in a sample, but it is also possible that different elements are bonded without introducing chemical shift. It is usually a challenging work to properly calibrate a XPS spectrum and resolve differently shifted components (peaks) from electrons of the same shell in order to draw correct conclusions.

The quantification of the chemical composition or between chemically shifted components can also be obtained from the acquired spectrum by comparing areas under the peaks and applying a proper relative sensitivity factor (RSF) for each element. Briefly speaking, the former represents the population of electrons with certain binding energy, while the RSF is to compensate the different electron emission cross-sections from various electron states of different elements. 


\section{Summary of Included Papers}

\subsection{Discovery of a new nanolaminated carbide, $\mathrm{Mo}_{2} \mathrm{Ga}_{2} \mathrm{C}$ (Paper I)}

In Paper I, synthesis of a new nanolaminated phase in the Mo-Ga-C system was reported in both bulk and thin film form with Mo atomic layers interleaved by double Ga atomic layers as observed in STEM micrographs and EDX composition mapping.

Based on the structural analysis of micrographs and XRD patterns, as well as current knowledge of existing nanolaminated phases, a postulation was made for the crystal structure of this new phase. A layered structure similar to $\mathrm{Mo}_{2} \mathrm{GaC}$ was suggested, the only known MAX phase in Mo-Ga-C system, but with Ga-double layers instead of single layers as in the known MAX phases, making its chemical formula $\mathrm{Mo}_{2} \mathrm{Ga}_{2} \mathrm{C}$. To support the postulation, ToF-ERDA experiment was done to show an overall composition of a thin film sample close to $\mathrm{Mo}_{2} \mathrm{Ga}_{2} \mathrm{C}$, while XRD Rietveld analysis also agreed with the structure when comparing to the powder diffraction pattern.

\subsection{Structural determination of the new carbide, $\mathrm{Mo}_{2} \mathrm{Ga}_{2} \mathrm{C}$ (Paper II)}

Following the Paper I, where the atomic position of carbon in the crystal structure of $\mathrm{Mo}_{2} \mathrm{Ga}_{2} \mathrm{C}$ could not be confirmed due to lower detectable contrasts in the presence of much heavier elements (Mo and Ga), both theoretical and experimental evidence was provided in Paper II to support the previous postulation.

Results from first principles calculations confirmed that the structure proposed in Paper I, i.e. with $\mathrm{C}$ atoms between two Mo layers and with Ga-double layer stacking in simple hexagon, is the only 
stable structure for $\mathrm{Mo}_{2} \mathrm{Ga}_{2} \mathrm{C}$ among range of structures simulated. The Rietveld analysis of the neutron powder diffraction pattern of a powder sample was also consistent with the structure suggested from the calculations. Moreover, indirect evidence was presented by STEM micrographs with EDX maps, where a smooth transition appears between $\mathrm{Mo}_{2} \mathrm{GaC}$ and $\mathrm{Mo}_{2} \mathrm{Ga}_{2} \mathrm{C}$ with an insertion of Ga layer, and by XPS analysis, where the two carbides are structurally and chemically very alike each other. Thus, by combining the results of all above independent theoretical and experimental methods, the postulation in Paper I was validated and the crystal structure was concluded.

\subsection{Phase stability of $\mathrm{Zr}_{2} \mathrm{Al}_{3} \mathrm{C}_{4}$ in thin film synthesis (Paper III)}

In Paper III, the phase stability of $\mathrm{Zr}_{2} \mathrm{Al}_{3} \mathrm{C}_{4}$, another nanolaminated carbide, was studied with respect to its crystal quality, together with the formation of other possible phases (competing phases) in thin film samples.

The result showed that the formation of $\mathrm{Zr}_{2} \mathrm{Al}_{3} \mathrm{C}_{4}$ is more competitive compared to other phases on a substrate material with smaller interfacial lattice mismatch, at higher deposition temperature, and with supersaturation of $\mathrm{Al}$ content during growth. For the condition where $\mathrm{Zr}_{2} \mathrm{Al}_{3} \mathrm{C}_{4}$ becomes less favorable, competing phases such as $\mathrm{ZrC}$ and $\mathrm{ZrAl}_{3}$ starts to grow in films. Hence, $\mathrm{Zr}_{2} \mathrm{Al}_{3} \mathrm{C}_{4}$ phase can have a growth behavior very much similar to MAX phases in thin film synthesis, despite they are quite different in their structures and chemical bonding for the A (in MAX phases) or Al-C (in $\mathrm{Zr}_{2} \mathrm{Al}_{3} \mathrm{C}_{4}$ ) layers. This is also the first report on $\mathrm{Zr}_{2} \mathrm{Al}_{3} \mathrm{C}_{4}$ thin films with indications on paths for improving the phase purity and crystal quality by controlling the growth conditions. 


\section{Outlines for Future Work}

Studying materials is usually driven by their properties of interest in relation to requirements of certain applications. This also applies to the materials in this work, where $\mathrm{Mo}_{2} \mathrm{Ga}_{2} \mathrm{C}$ is fundamentally interesting for properties of Mo-C planes proposed in the literature, and $\mathrm{Zr}_{2} \mathrm{Al}_{3} \mathrm{C}_{4}$ for its possible applications as protective coatings. Moreover, for the nanolaminated materials, the mechanisms behind their unique properties, presumably originating from the repeated layers, are not yet fully explained.

An extension of this work is to explore the possible nanolaminated carbide family with a general chemical formula $M_{2} A_{2} \mathrm{C}$, or even $M_{n+1} A_{2} \mathrm{C}_{n}$, which can be closely related to the MAX phases as indicated by $\mathrm{Mo}_{2} \mathrm{Ga}_{2} \mathrm{C}$ and $\mathrm{Mo}_{2} \mathrm{GaC}$. This can be realized by two steps. The first is to look for $M_{2} \mathrm{Ga}_{2} \mathrm{C}$ phases where the $M$ element is a transition metal other than Mo, completely or partially substituting $\mathrm{Mo}$ in $\mathrm{Mo}_{2} \mathrm{Ga}_{2} \mathrm{C}$ phase. The other route is to look for other $M_{2} A_{2} \mathrm{C}$ phases with $A$ element other than $\mathrm{Ga}$, for example $A=\mathrm{Al}, \mathrm{In}, \mathrm{Si}$ and $\mathrm{Ge}$. It would be interesting to compare the two similar families, elaborating the connection between the changes in their properties and in their structures, i.e. the insertion of an extra $A$ layer.

In another direction, future work can invole studying the growth of nanolaminated carbides within different thin film deposition techniques. Specifically, most studies of layered carbide thin films are carried out with DCMS, which has very limited kinetic energy of the depositing species. Information about phase stability and adatom kinetics can be studied in thin films deposited with 
other techniques resulting in higher incoming ion energy, e.g. cathodic arc deposition. For example, a comparative study of $\mathrm{Zr}_{2} \mathrm{Al}_{3} \mathrm{C}_{4}$ phase deposited with DCMS can be related to this work, or as another example, MAX phases in Ti-Ge-C system, which have previously only been studied with DCMS, can be deposited with arc deposition. 


\section{Bibliography}

[1] L. Toth, Transition Metal Carbides and Nitrides, Academic Press Inc., New York, USA, 1971.

[2] C. M. Fernandes and A. M. R. Senos, Cemented carbide phase diagrams: A review, Int. J. Refract. Met. H. 29 (2011) 405-418.

[3] Å. Öberg, Å. Kassman, B. André, U. Wiklund, M. Lindquist, E. Lewin, U. Jansson, H. Högberg, T. Joelsson, and H. Ljungcrantz, Conductive nanocomposite ceramics as tribological and electrical contact materials, Eur. Phys. J. Appl. Phys. 49 (2010) 22902.

[4] D. Martínez-Martínez, C. López-Cartes, A. Fernández, and J. C. Sánchez-López, Influence of the microstructure on the mechanical and tribological behavior of TiC/a-C nanocomposite coatings, Thin Solid Films 517 (2009) 1662-1671.

[5] F. Solymosi, A. Szöke, and J. Cserényi, Conversion of methane to benzene over $\mathrm{Mo}_{2} \mathrm{C}$ and $\mathrm{Mo}_{2} \mathrm{C} / \mathrm{ZSM}-5$ catalysts, Catal. Lett. 39 (1996) 157-161.

[6] W. S. Williams, Transition-Metal Carbides, Prog. Solid State Chem. 6 (1971) 57-118.

[7] Sir W. Ramsay, Moissan Memorial Lecture, J. Chem. Soc., Trans. 101 (1912) 477-488.

[8] G. V. Samsonov and V. A. Obolonchik, Frederic Henri Moissan, on the 120th Anniversary of His Birth, Sov. Powder Metall. Metal Ceram. 11 (1972) 766-768.

[9] Z. Yao, J. J. Stiglich, and T. S. Sudarshan, WC-Co enjoys proud history and bright future, Metal Pow. Rep. 53 (1998) 32-36.

[10] W. S. Williams, Physics of Transition Metal Carbides, Mater. Sci. Eng. A105/106 (1988) 1-10.

[11] J. C. Schuster and H. Nowotny, Investigations of the ternary systems ( $\mathrm{Zr}, \mathrm{Hf}, \mathrm{Nb}, \mathrm{Ta})-\mathrm{Al}-\mathrm{C}$ and studies on complex carbides, Z. Metallkd. 71 (1980) 341-346.

[12] H. Nowotny, P. Rogl, and J. C. Schuster, Structural chemistry of complex carbides and related compounds, $J$. Solid State Chem. 44 (1982) 126-133.

[13] H. Holleck, Material selection for hard coatings, J. Vac. Sci. Technol. A 4 (1986) 2661-2669.

[14] T. M. Gesing, K. H. Wachtmann, and W. Jeitschko, The Perovskite Carbides $A_{3} M C$ ( $A=\mathrm{Sc}, \mathrm{Y}, \mathrm{La}-\mathrm{Nd}, \mathrm{Sm}$, $\mathrm{Gd}-\mathrm{Lu} ; M=\mathrm{Al}, \mathrm{Ga}, \mathrm{In}, \mathrm{Tl}, \mathrm{Sn}, \mathrm{Pb})$, Z. Naturforsch. 52 b (1997) 176-182.

[15] M. W. Barsoum, The $M_{N+1} A X_{N}$ Phases: A New Class of Solids; Thermodynamically Stable Nanolaminates, Prog. Solid St. Chem. 28 (2000) 201-281. 
[16] P. Eklund, M. Beckers, U. Jansson, H. Högberg, and L. Hultman, The $M_{n+1} A X_{n}$ phases: Materials science and thin-film processing, Thin Solid Films 518 (2010) 1851-1878.

[17] L. E. Toth, High superconducting transition temperatures in the molybdenum carbide family of compounds, $J$. Less-Common Metals 13 (1967) 129-131.

[18] V. Sadagapan and H. C. Gatos, Superconductivity in the transition metal carbides: $\mathrm{Mo}_{4.8} \mathrm{Si}_{3} \mathrm{C}_{0.6}, \mathrm{Mo}_{0.95} \mathrm{Hf}_{0.05} \mathrm{C}_{0.75}$ and $\mathrm{Mo}_{2} \mathrm{C}$, J. Phys. Chem. Solids 27 (1966) 235-238.

[19] C. Xu, L. Wang, Z. Liu, L. Chen, J. Guo, N. Kang, X.-L. Ma, H.-M. Cheng, and W. Ren, Large-area high-quality 2D ultrathin $\mathrm{Mo}_{2} \mathrm{C}$ superconducting crystals, Nat. Mater. (2015).

[20] J. C. Schlatter, S. T. Oyama, J. E. Metcalfe, III, and J. M. Lambert, Jr., Catalytic behavior of selected transitionmetal carbides, nitrides, and borides in the hydrodenitrogenation of quinoline, Ind. Eng. Chem. Res. 27 (1988) 1648-1653.

[21] W.-F. Chen, C.-H. Wang, K. Sasaki, N. Marinkovic, W. Xu, J. T. Muckerman, Y. Zhu, and R. R. Adzic, Highly active and durable nanostructured molybdenum carbide electrocatalysts for hydrogen production, Energy Environ. Sci. 6 (2013) 943-951.

[22] W. O. Winer, Molybdenum disulfide as a lubricant: A review of the fundamental knowledge, Wear 10 (1967) 422-452.

[23] T. Spalvins, Morphological and frictional behavior of sputtered $\mathrm{MoS}_{2}$ films, Thin Solid Films 96 (1982) 17-24.

[24] M. Khazaei, M. Arai, T. Sasaki, M. Estili, and Y. Sakka, Two-dimensional molybdenum carbides: potential thermoelectric materials of the MXene family, Phys. Chem. Chem. Phys. 16 (2014) 7841-7849.

[25] R. Meshkian, L.-Å. Näslund, J. Halim, J. Lu, M. W. Barsoum, and J. Rosen, Synthesis of two-dimensional molybdenum carbide, $\mathrm{Mo}_{2} \mathrm{C}$, from the gallium based atomic laminate $\mathrm{Mo}_{2} \mathrm{Ga}_{2} \mathrm{C}$, Scripta Mater. 108 (2015) 147 150.

[26] V. F. Sears, Neutron scattering lengths and cross sections, Neutron News 3 (1992) 26-37.

[27] K. Fukuda, S. Mori, and S. Hashimoto, Crystal structure of $\mathrm{Zr}_{2} \mathrm{Al}_{3} \mathrm{C}_{4}$, J. Am. Ceram. Soc. 88 (2005) 3528-3530.

[28] L. F. He, Y. C. Zhou, Y. W. Bao, Z. J. Lin, and J. Y. Wang, Synthesis, physical, and mechanical properties of bulk $\mathrm{Zr}_{3} \mathrm{Al}_{3} \mathrm{C}_{5}$ ceramic, J. Am. Ceram. Soc. 90 (2007) 1164-1170.

[29] D. R. Secrist, Compound formation in the systems lithium-carbon and lithium-boron, J. Am. Ceram. Soc 50 (1967) 520-523.

[30] M. A. Bredig, The polymorphism of calcium carbide, J. Phys. Chem. 46 (1942) 801-819.

[31] R. C. Vickery, R. Sedlacek, and A. Ruben, 103. Rare-earth carbides. Part I, J. Chem. Soc. (1959) 498-503.

[32] H. O. Pierson, The Refractory Carbides in: Handbook of Refractory Carbides \& Nitrides: Properties, Characteristic, Processing and Applications, Noyes Publications, New Jersey, USA, 1996, pp. 8-16.

[33] U. Jansson and E. Lewin, Sputter deposition of transition-metal carbide films - A critical review from a chemical perspective, Thin Solid Films 536 (2013) 1-24.

[34] S. V. Meschel and O. J. Kleppa, Standard enthalpies of formation of some 3d transition metal carbides by high temperature reaction calorimetry, J. Alloy. Compd. 257 (1997) 227-233.

[35] D. H. Jack and K. H. Jack, Invited review: Carbides and nitrides in steel, Mater. Sci. Eng. 11 (1973) 1-27.

[36] V. N. Lipatnikov, A. I. Gusev, P. Ettmayer, and W. Lengauer, Phase transformations in non-stoichiometric vanadium carbide, J. Phys.: Condens. Matter 11 (1999) 163-184.

[37] A. I. Gusev and A. A. Rempel, Order-disorder phase transition channel in niobium carbide, Phys. Stat. Sol. 93 (1986) 71-80.

[38] A. I. Gusev, A. A. Rempel, and V. N. Lipatnikov, Incommensurate ordered phase in non-stoichiometric tantalum carbide, J. Phys.: Condens. Matter 8 (1996) 8277-8293. 
[39] H. W. Hugosson, O. Eriksson, L. Nordström, U. Jansson, L. Fast, A. Delin, J. M. Wills, and B. Johansson, Theory of phase stabilities and bonding mechanisms in stoichiometric and substoichiometric molybdenum carbide, $J$. Appl. Phys. 86 (1999) 3758-3767.

[40] A. S. Kurlov and A. I. Gusev, Phase equilibria in the W-C system and tungsten carbides, Russ. Chem. Rev. 75 (2006) 617-636.

[41] S. J. Wang, H. Y. Tsai, and S. C. Sun, Characterization of sputtered titanium carbide film as diffusion barrier for copper metallization, J. Electrochem. Soc. 148 (2001) C563-C568.

[42] T. Laurila, K. Zeng, J. K. Kivilahti, J. Molarius, T. Riekkinen, and I. Suni, Tantalum carbide and nitride diffusion barriers for Cu metallisation, Microelectron. Eng. 60 (2002) 71-80.

[43] C. R. Wang, J.-M. Yang, and W. Hoffman, Thermal stability of refractory carbide/boride composites, Mater. Chem. Phys. 74 (2002) 272-281.

[44] P. Barnier and F. Thévenot, Synthesis and hot-pressing of single-phase $\mathrm{ZrC}_{x} \mathrm{O}_{y}$ and two-phase $\mathrm{ZrC}_{x} \mathrm{O}_{y}-\mathrm{ZrO}_{2}$ materials, Int. J. High Techno. Ceram. 2 (1986) 291-307.

[45] M. M. Opeka, I. G. Talmy, E. J. Wuchina, J. A. Zaykoski, and S. J. Causey, Mechanical, thermal, and oxidation properties of refractory hafnium and zirconium compounds, J. Eur. Ceram. Soc. 19 (1999) 2405-2414.

[46] S. Zhang, Titanium carbonitride-based cermets: processes and properties, Mater. Sci. Eng. A163 (1993) 141148.

[47] G. S. Upadhyaya, Material science of cemented carbides - an overview, Mater. Design 22 (2001) 483-489.

[48] J. Poetschke, V. Richter, and R. Holke, Influence and effectivity of $\mathrm{VC}$ and $\mathrm{Cr}_{3} \mathrm{C}_{2}$ grain growth inhibitors on sintering of binderless tungsten carbide, Int. J. Refract. Met. H. 31 (2012) 218-223.

[49] H. Holleck, The effect of carbon on the occurrence of $\mathrm{Cu}_{3} \mathrm{Au}$-type phases in actinide and lanthanide-platinum metal systems, J. Nucl. Mater. 42 (1972) 278-284.

[50] A. I. Gusev, Phase equilibria in $M-X-X^{\prime}$ and $M$-Al- $X$ ternary systems ( $M=$ transition metal; $\left.X, X^{\prime}-\mathrm{B}, \mathrm{C}, \mathrm{N}, \mathrm{Si}\right)$ and the crystal chemistry of ternary compounds, Russ. Chem. Rev. 65 (1996) 379-419.

[51] M. Naguib, G. W. Bentzel, J. Shah, J. Halim, E. N. Caspi, J. Lu, L. Hultman, and M. W. Barsoum, New solid solution MAX phases: $\left(\mathrm{Ti}_{0.5}, \mathrm{~V}_{0.5}\right)_{3} \mathrm{AlC}_{2},\left(\mathrm{Nb}_{0.5}, \mathrm{~V}_{0.5}\right)_{2} \mathrm{AlC},\left(\mathrm{Nb}_{0.5}, \mathrm{~V}_{0.5}\right)_{4} \mathrm{AlC}_{3}$ and $\left(\mathrm{Nb}_{0.8}, \mathrm{Zr}_{0.2}\right)_{2} \mathrm{AlC}$, Mater. Res. Lett. 2 (2014) 233-240.

[52] A. Mockute, M. Dahlqvist, J. Emmerlich, L. Hultman, J. M. Schneider, P. O. Å. Persson, and J. Rosen, Synthesis and ab initio calculations of nanolaminated (Cr,Mn) ${ }_{2} \mathrm{AlC}$ compounds, Phys. Rev. B 87 (2013) 094113.

[53] J. Etzkorn, M. Ade, D. Kotzott, M. Kleczek, and H. Hillebrecht, $\mathrm{Ti}_{2} \mathrm{GaC}_{2} \mathrm{Ti}_{4} \mathrm{GaC}_{3}$ and $\mathrm{Cr}_{2} \mathrm{GaC}-\mathrm{Synthesis}$, crystal growth and structure analysis of Ga-containing MAX-phases $M_{n+1} \mathrm{GaC}_{n}$ with $M=\mathrm{Ti}, \mathrm{Cr}$ and $n=1,3, J$. Solid State Chem. 182 (2009) 995-1002.

[54] W. Yu, V. Gauthier-Brunet, T. Cabioc'h, and S. Dubois, Synthesis and microstructural characterization of substoichiometric $\mathrm{Ti}_{2} \mathrm{Al}\left(\mathrm{C}_{x} \mathrm{~N}_{y}\right)$ solid solutions and related $\mathrm{Ti}_{2} \mathrm{AlC}_{x}$ and $\mathrm{Ti}_{2} \mathrm{AlN}$ end-members, J. Am. Ceram. Soc. 97 (2014) 2308-2313.

[55] Z. Liu, L. Zheng, L. Sun, Y. Qian, J. Wang, and M. Li, $\left(\mathrm{Cr}_{2 / 3} \mathrm{Ti}_{1 / 3}\right)_{3} \mathrm{AlC}_{2}$ and $\left(\mathrm{Cr}_{5 / 8} \mathrm{Ti}_{3 / 8}\right)_{4} \mathrm{AlC}_{3}$ : New MAX-phase Compounds in Ti-Cr-Al-C System, J. Am. Ceram. Soc. 97 (2014) 67-69.

[56] E. N. Caspi, P. Chartier, F. Porcher, F. Damay, and T. Cabioc'h, Ordering of $(\mathrm{Cr}, \mathrm{V})$ layers in nanolamellar $\left(\mathrm{Cr}_{0.5} \mathrm{~V}_{0.5}\right)_{n+1} \mathrm{AlC}_{n}$ compounds, Mater. Res. Lett. 3 (2015) 100-106.

[57] B. Anasori, J. Halim, J. Lu, C. A. Voigt, L. Hultman, and M. W. Barsoum, $\mathrm{Mo}_{2} \mathrm{TiAlC}_{2}$ : A new ordered layered ternary carbide, Scripta Mater. 101 (2015) 5-7.

[58] K. Fukuda and M. Hisamura, $\mathrm{Cr}$ ystal structure and thermoelectric properties of $\mathrm{YAl}_{3} \mathrm{C}_{3}$, J. Am. Ceram. Soc. 90 (2007) 3299-3302. 
[59] K. Sugiura, T. Iwata, H. Yoshida, S. Hashimoto, and K. Fukuda, Syntheses, crystal structures and Si solubilities of new layered carbides $\mathrm{Zr}_{2} \mathrm{Al}_{4} \mathrm{C}_{5}$ and $\mathrm{Zr}_{3} \mathrm{Al}_{4} \mathrm{C}_{6}$, J. Solid State Chem. 181 (2008) 2864-2868.

[60] Y. C. Zhou, L. F. He, Z. J. Lin, and J. Y. Wang, Synthesis and structure-property relationships of a new family of layered carbides in $\mathrm{Zr}-\mathrm{Al}(\mathrm{Si})-\mathrm{C}$ and $\mathrm{Hf}-\mathrm{Al}(\mathrm{Si})-\mathrm{C}$ systems, J. Euro. Ceram. Soc. 33 (2013) 2831-2865.

[61] T. M. Gesing and W. Jeitschko, The crystal structures of $\mathrm{Zr}_{3} \mathrm{Al}_{3} \mathrm{C}_{5}, \mathrm{ScAl}_{3} \mathrm{C}_{3}$, and $\mathrm{UAl}_{3} \mathrm{C}_{3}$ and their relation to the structures of $\mathrm{U}_{2} \mathrm{Al}_{3} \mathrm{C}_{4}$ and $\mathrm{Al}_{4} \mathrm{C}_{3}$, J. Solid State Chem. 140 (1998) 396-401.

[62] T. M. Gesing, R. Pöttgen, W. Jeitschko, and U. Wortmann, Crystal structure and physical properties of the carbides $\mathrm{UAl}_{3} \mathrm{C}_{3}$ and $\mathrm{YbAl}_{3} \mathrm{C}_{3}$, J. Alloy. Compd. 186 (1992) 321-331.

[63] T. Iwata, E. Hattori, S. Hashimoto, and K. Fukuda, Synthesis and crystal structure of a new layered carbide $\mathrm{ZrAl}_{4} \mathrm{C}_{4}$, J. Am. Ceram. Soc. 91 (2008) 2713-2715.

[64] H. Nian, L. He, F. Li, J. Wang, and Y. Zhou, Crystal structure and theoretical elastic property of a new ternary ceramic $\mathrm{HfAl}_{4} \mathrm{C}_{4}$, J. Am. Ceram. Soc. 93 (2010) 1164-1168.

[65] C. Hu, C.-C. Lai, Q. Tao, J. Lu, J. Halim, L. Sun, J. Zhang, J. Yang, B. Anasori, J. Wang, Y. Sakka, L. Hultman, P. Eklund, J. Rosen, and M. W. Barsoum, $\mathrm{Mo}_{2} \mathrm{Ga}_{2} \mathrm{C}$ : A new ternary nanolaminated carbide, Chem. Commun. 51 (2015) 6560.

[66] C.-C. Lai, R. Meshkian, M. Dahlqvist, J. Lu, L.-Å. Näslund, O. Rivin, E. N. Caspi, O. Ozeri, L. Hultman, P. Eklund, M. W. Barsoum, and J. Rosen, Structural and chemical determination of the new nanolaminated carbide $\mathrm{Mo}_{2} \mathrm{Ga}_{2} \mathrm{C}$ from first principles and materials analysis, Acta Mater. 99 (2015) 157-164.

[67] J. Emmerlich, D. Music, M. Braun, P. Fayek, F. Munnik, and J. M. Schneider, A proposal for an unusually stiff and moderately ductile hard coating material: $\mathrm{Mo}_{2}$ BC, J. Phys. D: Appl. Phys. 42 (2009) 185406.

[68] T. El-Raghy, A. Zavaliangos, M. W. Barsoum, and S. R. Kalidindi, Damage mechanisms around hardness indentations in $\mathrm{Ti}_{3} \mathrm{SiC}_{2}$, J. Am. Ceram. Soc. 80 (1997) 513-516.

[69] B. J. Kooi, R. J. Poppen, N. J. M. Carvalho, J. Th. M. De Hosson, and M. W. Barsoum, $\mathrm{Ti}_{3} \mathrm{SiC}_{2}$ : A damage tolerant ceramic studied with nanoindentations and transmission electron microscopy, Acta Mater. 51 (2003) 2859-2872.

[70] Z. M. Sun, A. Murugaiah, T. Zhen, A. Zhou, and M. W. Barsoum, Microstructure and mechanical properties of porous $\mathrm{Ti}_{3} \mathrm{SiC}_{2}$, Acta Mater. 53 (2005) 4359-4366.

[71] M. W. Barsoum, T. Zhen, A. Zhou, S. Basu, and S. R. Kalidindi, Microscale modeling of kinking nonlinear elastic solids, Phys. Rev. B 71 (2005) 134101.

[72] B. Poon, L. Ponson, J. Zhao, and G. Ravichandran, Damage accumulation and hysteretic behavior of MAX phase materials, J. Mech. Phys. Solids 59 (2011) 2238-2257.

[73] M. Ohring, The Materials Science of Thin Films, Academic Press, California, USA, 1992.

[74] A. C. Jones and M. L. Hitchman, Chapter 1 Overview of Chemical Vapour Deposition in: Chemical Vapour Deposition: Precursors, Processes and Applications, A. C. Jones and M. L. Hitchman, Eds., The Royal Society of Chemistry, Cambridge, UK, 2009, p. 1.

[75] R. Gago, L. Vázquez, R. Cuerno, M. Varela, C. Ballesteros, and J. M. Albella, Nanopatterning of silicon surfaces by low-energy ion-beam sputtering: dependence on the angle of ion incidence, Nanotechnol. 13 (2002) 304-308.

[76] H. Adachi and K. Wasa, Part I Fundamentals of Sputtering in: Handbook of Sputter Deposition Technology 2nd ed., Elsevier, Oxford, UK, 2012, pp. 1-140.

[77] D. W. Hoffman and J. A. Thornton, Compressive stress and inert gas in Mo films sputtered from a cylindricalpost magnetron with Ne, Ar, Kr, and Xe, J. Vac. Sci. Technol. 17 (1980) 380-383.

[78] I. Petrov, I. Ivanov, V. Orlinov, and J.-E. Sundgren, Comparison of magnetron sputter deposition conditions in neon, argon, krypton, and xenon discharges, J. Vac. Sci. Technol. A 11 (1993) 2733-2741. 
[79] P.J.Kelly and R.D.Arnell, Magnetron sputtering: a review of recent developments and applications, Vacuum 56 (2000) 159-172.

[80] J. A. Thornton and A. S. Penfold, II-2 Cylindrical Magnetron Sputtering in: Thin Film Processes, J. L. Vossen and W. Kern, Eds., Academic Press, New York, USA, 1978, pp. 76-114.

[81] K. Sarakinos, J. Alami, and S. Konstantinidis, High power pulsed magnetron sputtering: A review on scientific and engineering state of the art, Surf. Coat. Technol. 204 (2010) 1661-1684.

[82] A. Anders, Unfiltered and filtered cathodic arc deposition in: Handbook of Deposition Technologies for Films and Coatings 3rd ed., P. M. Martin, Ed., Elsevier, Oxford, UK, 2010, pp. 466-531.

[83] A. Anders, 3 The Physics of Cathode Processes in: Cathodic Arcs: From Fractal Spots to Energetic Condensation, Springer Science + Business Media, New York, USA, 2008, pp. 75-174.

[84] B. Jütter, Characaterization of the Cathode Spot, IEEE Trans. Plasma Sci. PS-15 (1987) 474-480.

[85] D. M. Sanders and A. Anders, Review of cathodic arc deposition technology at the start of the new millennium, Surf. Coat. Technol. 133-134 (2000) 78-90.

[86] R. L. Boxman and V. N. Zhitomirsky, Vacuum arc deposition devices, Rev. Sci. Instrum. 77 (2006) 021101.

[87] L. Ryves, M. M. M. Bilek, T. W. H. Oates, R. N. Tarrant, D. R. McKenzie, F. A. Burgmann, and D. G. McCulloch, Synthesis and in-situ ellipsometric monitoring of Ti/C nanostructured multilayers using a highcurrent, dual source pulsed cathodic arc, Thin Solid Films 482 (2005) 133-137.

[88] P. Siemroth, T. Schülke, and T. Witke, High-current arc-a new source for high-rate deposition, Surf. Coat. Technol. 68/69 (1994) 314-319.

[89] B. K. Gan, M. M. M. Bilek, D. R. McKenzie, P. D. Swift, and G. McCredie, Optimizing the triggering mode for stable operation of a pulsed cathodic arc deposition system, Plasma Sources Sci. Technol. 12 (2003) 508-512.

[90] A. Anders, Approaches to rid cathodic arc plasma of macro- and nanoparticles: a review, Surf. Coat. Technol. 120-121 (1999) 319-330.

[91] E. Bauer, Z. Kristallogr. 110 (1958) 372-394.

[92] H. Holleck, Metastable coatings - Predection of composition and structure, Surf. Coat. Technol. 36 (1988) 151159.

[93] I. Petrov, P. B. Barna, L. Hultman, and J. E. Greene, Microstructural evolution during film growth, J. Vac. Sci. Technol. A 21 (2003) S117-S128.

[94] I. Petrov, L. Hultman, U. Helmersson, J.-E. Sundgren, and J. E. Greene, Microstructure modification of TiN by ion bombardment during reactive sputter deposition, Thin Solid Films 169 (1989) 299-314.

[95] U. Helmersson, M. Lattemann, J. Bohlmark, A. P. Ehiasarian, and J. T. Gudmundsson, Ionized physical vapor deposition (IPVD): A review of technology and applications, Thin Solid Films 513 (2006) 1-24.

[96] A. Anders, A review comparing cathodic arcs and high power impulse magnetron sputtering (HiPIMS), Surf. Coat. Technol. 257 (2014) 308-325.

[97] A. Anders, A structure zone diagram including plasma-based deposition and ion etching, Thin Solid Films 518 (2010) 4087-4090. 


\section{Pending Papers}

The articles associated with this thesis have been removed for copyright reasons. For more details about these see:

http://urn.kb.se/resolve?urn=urn:nbn:se:liu:diva-125289 